\title{
Hypoxia acts as an environmental cue for the human tissue-resident memory $T$ cell differentiation program
}

\author{
Farah Hasan, ${ }^{1,2}$ Yulun Chiu, ${ }^{1}$ Rebecca M. Shaw, Junmei Wang, ${ }^{1}$ and Cassian Yee ${ }^{1,3}$ \\ 'Department of Melanoma Medical Oncology, University of Texas (UT) MD Anderson Cancer Center, Houston, Texas, USA \\ ${ }^{2}$ MD Anderson Cancer Center UTHealth Graduate School of Biomedical Sciences, Houston, Texas, USA. ${ }^{3}$ Department of \\ Immunology, UT MD Anderson Cancer Center, Houston, Texas, USA.
}

Tissue-resident memory $T$ cells $\left(T_{R M}\right)$ provide frontline defense against infectious diseases and contribute to antitumor immunity; however, aside from the necessity of TCF- $\beta$, knowledge regarding $\mathrm{T}_{\mathrm{RM}}$-inductive cues remains incomplete, particularly for human cells. Oxygen tension is an environmental cue that distinguishes peripheral tissues from the circulation, and here, we demonstrate that differentiation of human CD8+ $\mathrm{T}$ cells in the presence of hypoxia and TCF- $\beta 1$ led to the development of a $\mathrm{T}_{\mathrm{RM}}$ phenotype, characterized by a greater than $\mathbf{5}$-fold increase in $\mathrm{CD} 9^{+} \mathrm{CD}_{103}{ }^{+}$cells expressing human $\mathrm{T}_{\mathrm{RM}}$ hallmarks and enrichment for endogenous human $\mathrm{T}_{\mathrm{RM}}$ gene signatures, including increased adhesion molecule expression and decreased expression of genes involved in recirculation. Hypoxia and TCF- $\beta 1$ synergized to produce a significantly larger population of $\mathrm{T}_{\mathrm{RM}}$ phenotype cells than either condition alone, and comparison of these cells from the individual and combination conditions revealed distinct phenotypic and transcriptional profiles, indicating a programming response to milieu rather than a mere expansion. Our findings identify a likely previously unreported cue for the $\mathrm{T}_{\mathrm{RM}}$ differentiation program and can enable facile generation of human $\mathrm{T}_{\mathrm{RM}}$ phenotype cells in vitro for basic studies and translational applications such as adoptive cellular therapy.

\section{Conflict of interest: $\mathrm{CY}$ is a consultant/advisory board member for Affylmmune Therapeutics, Inc.; Immatics; and Obsidian Therapeutics. A patent application based on this manuscript has been filed ( $\mathrm{FH}$ and CY, PCT publication number WO 2020/081987 A1) \\ Copyright: (c) 2021, Hasan et al. This is an open access article published under the terms of the Creative Commons Attribution 4.0 International License.}

Submitted: April 9, 2020

Accepted: April 7, 2021

Published: May 24, 2021

Reference information: /CI Insight. 2021;6(10):e138970. https://doi.org/10.1172/jici. insight.138970.

\section{Introduction}

Tissue-resident memory $\mathrm{T}$ cells $\left(\mathrm{T}_{\mathrm{RM}}\right)$ are a recently defined subset of non-recirculating memory $\mathrm{T}$ cells that reside in peripheral tissues and are important in frontline defense against viral infections and associated with antitumor immunity. However, despite intense study, relatively little is known regarding $\mathrm{T}_{\mathrm{RM}}$ differentiation. Studies in mice have shown $\mathrm{CD} 8^{+} \mathrm{T}_{\mathrm{RM}}$ are seeded by early effector $\mathrm{T}$ cells that differentiate into resident memory in situ, likely in response to local cues $(1,2)$. These cues are thought to differ by tissue but remain poorly defined. TGF- $\beta$ is known to be critical in $T_{R M}$ establishment, and attempts to identify other resident phenotype inductive factors have focused on cytokines (1-9). Studies using mouse splenocytes 4 to 5 days postactivation have shown that TNF- $\alpha$ and IL-33 synergize with TGF- $\beta$ to induce an intestinal resident $\mathrm{T}$ cell phenotype $\left(\mathrm{CD} 103^{+} \mathrm{Ly}_{6} \mathrm{C}^{-} \mathrm{CD} 69^{+}\right)$as well as downregulation of the transcription factor Kruppel-like factor 2 (KLF2) and its target genes sphingosine-1 phosphate receptor 1 (S1PR1) and SELL (CD62L), which is required for $\mathrm{T}_{\mathrm{RM}}$ establishment $(4,10)$.

Oxygen tension is another factor that distinguishes peripheral tissues from the circulatory environment: typical physiological oxygen concentrations encountered by $\mathrm{T}$ cells can be as high as $10 \%$ to $12.5 \%$ in arterial blood and $3 \%$ to $6 \%$ in most healthy tissues and as low as $0.5 \%$ to $6 \%$ in the spleen and lymph nodes $(11-13)$. Notably, $\mathrm{T}_{\mathrm{RM}}$ were first described in barrier tissues, which are known to be relatively hypoxic $(1,14-18)$. In addition, any area of local inflammation can become hypoxic because of the increased density of metabolically active cells $(19,20)$. It has also been shown that oxygen consumption by activated neutrophils is sufficient to cause microenvironmental hypoxia (21). Thus, it is conceivable that the change in oxygen tension experienced by $\mathrm{T}$ cells in peripheral tissues and local inflammation could serve as a cue for the tissue residency program. We hypothesized that hypoxia may contribute to a TGF- $\beta 1$-induced $\mathrm{T}_{\mathrm{RM}}$ phenotype in human $\mathrm{CD}^{+} \mathrm{T}$ cells.

To date, the majority of studies on $\mathrm{T}_{\mathrm{RM}}$ have been conducted in mice as human studies are subject to more technical and regulatory constraints. Although there is considerable overlap between the phenotypes reported for mouse and human $\mathrm{T}_{\mathrm{RM}}$, there also appear to be key differences, notably illustrated by the differing 
importance of Hobit in $\mathrm{T}_{\mathrm{RM}}$ differentiation $(8,22-24)$. Such differences highlight the necessity for studying $\mathrm{T}_{\mathrm{RM}}$ differentiation in human cells, both to further understanding of basic molecular mechanisms and to facilitate effective translational application. Here, we demonstrate that human $\mathrm{T}$ cells differentiated during exposure to hypoxia and TGF- $\beta 1$ develop a $\mathrm{T}_{\mathrm{RM}}$ phenotype characterized by expression of protein markers and a transcriptional profile reminiscent of endogenous $\mathrm{T}_{\mathrm{RM}}$.

\section{Results}

Human $C D 8^{+} T$ cells differentiated in hypoxia and TGF- $\beta 1$ acquire a $T_{R M}$ phenotype. The necessity of TGF- $\beta$ in $\mathrm{T}_{\mathrm{RM}}$ formation is well documented, but additional cues are required, as TGF- $\beta$ alone is not sufficient to induce $\mathrm{T}_{\mathrm{RM}}$ phenotype $(4,8)$. Previous studies in mouse splenocytes demonstrated a role for inflammatory cytokines in $\mathrm{T}_{\mathrm{RM}}$ phenotype induction when used in combination with TGF- $\beta(4,10)$. Given the relative hypoxia in inflamed tissues, we postulated that low oxygen tension could provide additional cues for $\mathrm{T}_{\mathrm{RM}}$ differentiation. To determine whether hypoxia can contribute to induction of a $T_{R M}$ phenotype, we sorted naive $\left(\mathrm{CD} 45 \mathrm{RA}^{+} \mathrm{CCR} 7^{+}\right) \mathrm{CD}^{+} \mathrm{T}$ cells from human peripheral blood mononuclear cells (PBMCs), activated them for 4 days under hypoxia $\left(2 \% \mathrm{O}_{2}\right)$ or normal cell culture conditions $\left(\sim 20 \% \mathrm{O}_{2}\right)$ to generate "early effectors," and then cultured an additional 2 days in the presence of TGF- $\beta 1$ (25).

We used quantitative real-time PCR (qPCR) to assess the bulk populations for expression of a panel of $\mathrm{T}_{\mathrm{RM}}$-associated genes. Cells differentiated in $2 \% \mathrm{O}_{2}+\mathrm{TGF}-\beta 1$ showed upregulation of most of the genes Kumar et al. recently identified as the human $\mathrm{T}_{\mathrm{RM}}$ core signature, namely CD69, ITGAE (CD103), PDCD1 (programmed cell death 1 [PD-1]), CD101, and CXCR6 (Figure 1A and ref. 22). We did not observe a difference in ITGA1 (CD49a) transcript levels. In addition, transcripts of genes important in T cell recirculation (S1PR1, KLF2, SELL) were downregulated, further suggesting a residency program (Figure 1B). The downregulation of $S 1 P R 1$ and $K L F 2$ was previously shown to be critical to murine $\mathrm{T}_{\mathrm{RM}}$ differentiation, and decreased levels of these genes have also been observed in endogenous human $\mathrm{T}_{\mathrm{RM}}(10,22,23,26)$. Elevated expression of the canonical hypoxia-responsive genes $S L C 2 A 1$ and VEGFA confirmed the cells were responding to hypoxic conditions (Figure $1 \mathrm{C}$ ). Together, these results indicate that when human $\mathrm{CD} 8^{+} \mathrm{T}$ cells are differentiated under hypoxia in combination with TGF- $\beta 1$, they acquire a $\mathrm{T}_{\mathrm{RM}}$-like transcriptional profile.

We then evaluated protein-level expression of the core human $\mathrm{T}_{\mathrm{RM}}$ signature via flow cytometry (22). In all donors tested there was an increase in $\mathrm{CD} 69^{+} \mathrm{CD} 103^{+}$cells in the $2 \% \mathrm{O}_{2}+$ TGF- $\beta 1$ condition compared with $20 \% \mathrm{O}_{2}+$ TGF- $\beta 1$ (Figure 1D). Notably, unlike a previous report in mice, circulating naive human CD8 ${ }^{+}$ T cells did not appreciably express CD103 (ref. 27 and Supplemental Figure 1B; supplemental material available online with this article; https://doi.org/10.1172/jci.insight.138970DS1). Cell viability was comparable or better in $2 \% \mathrm{O}_{2}+$ TGF- $\beta 1$ versus $20 \% \mathrm{O}_{2}+$ TGF- $\beta 1$ (Supplemental Figure 1C). These CD $69^{+} \mathrm{CD}_{103}{ }^{+}$cells expressed CD49a, PD-1, and CD101; however, we did not observe CXCR6 surface protein expression despite transcriptional upregulation in the bulk population (Figure 1, A and E). Although CD69 and CD103 expression is commonly used to define $\mathrm{T}_{\mathrm{RM}}$, contention remains regarding which of these markers best denotes tissue residency, partly due to their heterogeneous expression in endogenous $\mathrm{T}_{\mathrm{RM}}$ (28). Thus, we compared expression levels of the $\mathrm{T}_{\mathrm{RM}^{-}}$-associated markers CD49a, PD-1, and CD101 among the CD69-CD103 ${ }^{+}, \mathrm{CD}^{-} 9^{+} \mathrm{CD} 103^{+}$, and $\mathrm{CD} 69^{+} \mathrm{CD} 103^{-}$populations from the $2 \% \mathrm{O}_{2}+$ TGF- $\beta 1$ condition. As expected, the $\mathrm{CD} 69^{+} \mathrm{CD} 103^{+}$population had the highest levels of PD-1 and CD101 surface expression (Supplemental Figure 1D). CD49a expression was also high but not significantly different from levels observed in the $\mathrm{CD} 69^{+} \mathrm{CD} 103^{-}$population. In comparing the 2 oxygen conditions, we found the most dramatic increase in population fold change to be in the $\mathrm{CD} 69^{+} \mathrm{CD} 103^{+}$population (Supplemental Figure 1, E and F). Based on these results, we focused further analysis on the $\mathrm{CD} 69^{+} \mathrm{CD} 103^{+}$population as our in vitro induced $\mathrm{T}_{\mathrm{RM}}$ cells (hereafter $\mathrm{i}-\mathrm{T}_{\mathrm{RM}}$ ).

Hypoxia and $T G F-\beta 1$ are synergistic cues for $T_{R M}$ phenotype acquisition. Since the atmospheric oxygen level of normal tissue culture conditions is higher than what $\mathrm{T}$ cells experience in vivo, we evaluated the effect of $10 \% \mathrm{O}_{2}$, which represents a physiologically relevant, nonhypoxic oxygen level in the circulation (11). Although there was a slight increase in $\mathrm{CD} 69^{+} \mathrm{CD} 103^{+} \mathrm{T}$ cells in $10 \% \mathrm{O}_{2}+$ TGF- $\beta 1$ compared with $20 \% \mathrm{O}_{2}$ + TGF- $\beta 1$, correcting for multiple comparisons showed no significant differences in $\mathrm{T}_{\mathrm{RM}}$-associated gene expression between the 2 conditions (Supplemental Figure 2, A-C). In addition, the fold increase of the $\mathrm{CD} 69^{+} \mathrm{CD}_{103}{ }^{+}$population over $20 \% \mathrm{O}_{2}+$ TGF- $\beta 1$ was significantly greater for the $2 \% \mathrm{O}_{2}+$ TGF- $\beta 1$ condition versus $10 \% \mathrm{O}_{2}+$ TGF- $\beta 1$ (Supplemental Figure 2D).

To assess the individual contributions of hypoxia and TGF- $\beta 1$ to generation of $\mathrm{T}_{\mathrm{RM}}$ phenotype cells, we performed in vitro differentiation experiments in $2 \%$ or $20 \% \mathrm{O}_{2}$ with or without TGF- $\beta 1$. Hypoxia primarily 
A

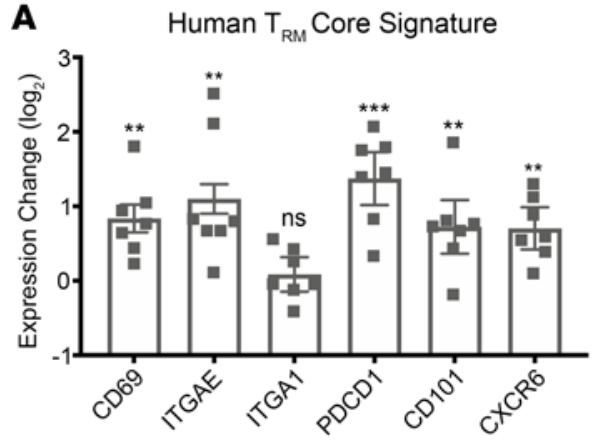

D
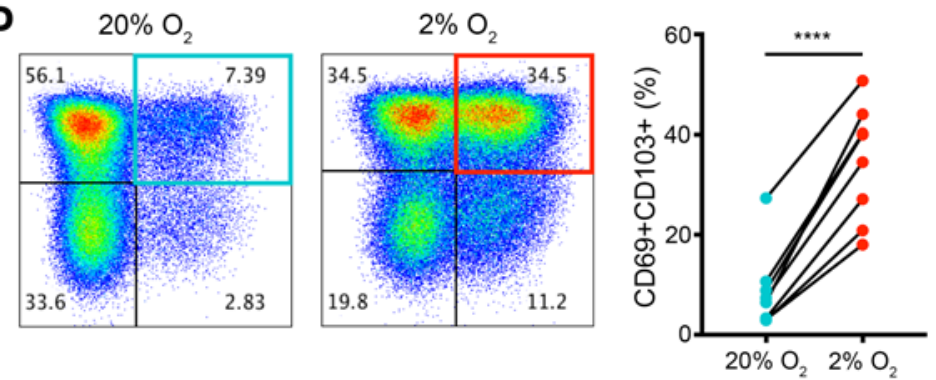

C Hypoxia Responsive Genes

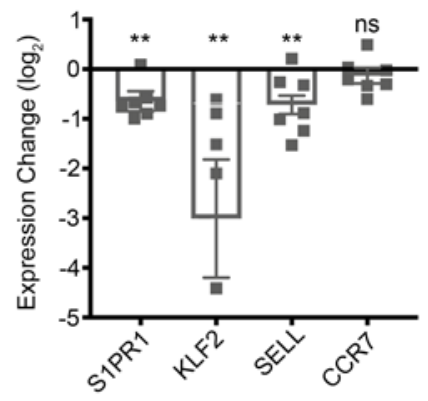

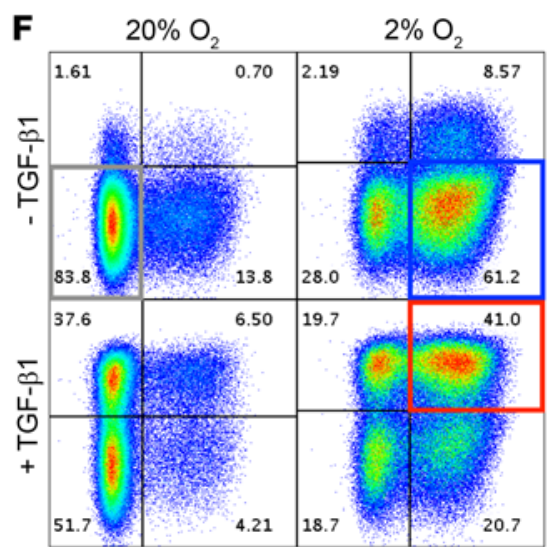

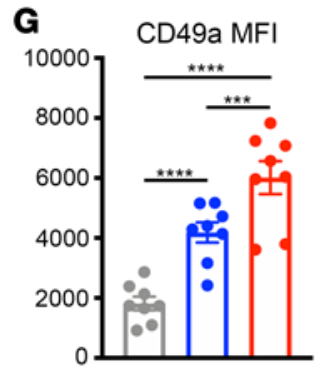

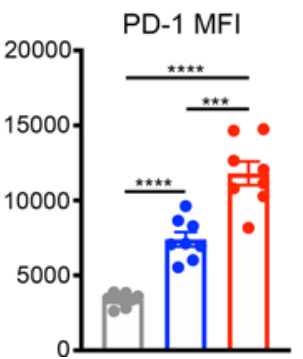

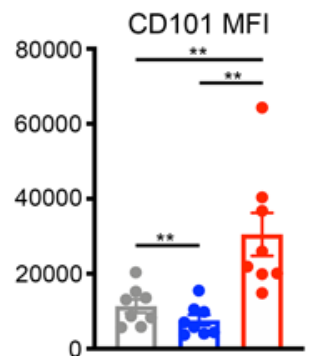

$\mathbf{E}$

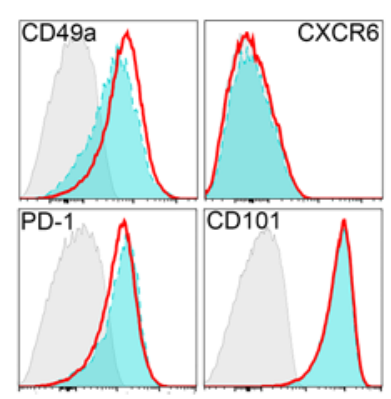

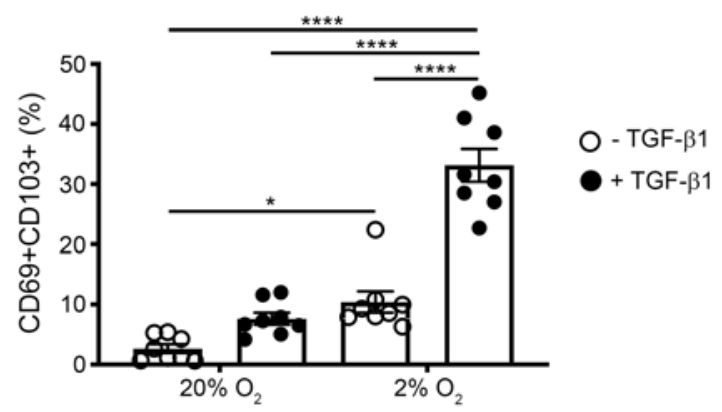

Figure 1. Hypoxia and TGF- $\beta 1$ synergize to induce a $C D 69^{+} C D 103^{+}$population that expresses human $\mathrm{T}_{\mathrm{pM}}$-associated markers. Naive $\mathrm{CD} 8^{+} \mathrm{T}$ cells sorted from PBMCs were activated in $20 \% \mathrm{O}_{2}\left(\mathrm{AtmosO}_{2}\right.$ ) or $2 \% \mathrm{O}_{2}$ (hypoxia) for 4 days and then for an additional 2 days with the addition of recombinant human TCF- $\beta 1$ (rhTGF- $\beta 1$ ). Expression levels of $\mathrm{T}_{\mathrm{RM}}$-associated genes were analyzed via quantitative real-time PCR. (A-C) Fold change of gene transcript levels in $2 \% \mathrm{O}_{2}+$ TCF- $\beta 1$ over $20 \% \mathrm{O}_{2}+$ TGF- $\beta 1$. (D) The frequency of the CD69 ${ }^{+} C D 103^{+} T_{R M}$-like population and (E) expression of $T_{R M}$-associated markers were assessed by flow cytometry. Representative results from 1 donor are shown ( $\mathbf{D}$ and $\mathbf{E}$ ). Blue histograms represent $\mathrm{CD69} \mathrm{C}^{+} \mathrm{CD} 103^{+}$cells from $20 \% \mathrm{O}_{2}+\mathrm{TCF}-\beta 1$, red histograms represent $\mathrm{CD}{ }^{+} \mathrm{CD}_{103}{ }^{+}$cells from $2 \% \mathrm{O}_{2}+$ TCF- $\beta 1$, and gray histograms represent fluorescence minus one (FMO). (A-C) $n=7$, 3 independent experiments; paired $t$ test with Benjamini, Krieger, and Yekutieli correction for multiple comparisons; ${ }^{* *} q<0.01,{ }^{* * *} q<0.001,{ }^{* * * *} q<0.0001$; FDR $<0.05$, data are mean \pm SEM. (D) $n=8$, 3 independent experiments; ratio paired $t$ test; ${ }^{* * *} P<0.0001$. Naive CD8 ${ }^{+}$T cells were activated in $20 \% \mathrm{O}_{2}$ or $2 \% \mathrm{O}_{2}$ for 4 days and then for an addition-

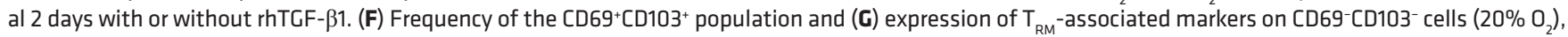
CD69+CD103- cells $\left(2 \% \mathrm{O}_{2}\right)$, and $\mathrm{CD}^{+} \mathrm{C}^{+} \mathrm{CD}_{103^{+}}$cells $\left(2 \% \mathrm{O}_{2}+\right.$ TCF- $\left.\beta 1\right)$ were assessed by flow cytometry; representative pseudocolor plots shown for 1 donor, $n=$ 8. Two-way ANOVA (F) or repeated measures 1-way ANOVA (G), ${ }^{*} P \operatorname{adj}<0.05,{ }^{* *} P a d j<0.01,{ }^{* * *} P a d j<0.001,{ }^{* * * *} P a d j<0.0001$; data are mean $\pm \mathrm{SEM}$. 
induced $\mathrm{CD} 69^{+}$cells whereas TGF- $\beta 1$ induced $\mathrm{CD} 103^{+}$cells, in congruence with reports that hypoxia and TGF- $\beta$ can drive expression of these markers, respectively (29-31). Although hypoxia or TGF- $\beta 1$ alone induced a modest population of $\mathrm{CD}^{+} 9^{+} \mathrm{CD} 103^{+}$cells, their combination appeared to synergize induction of $\mathrm{T}_{\mathrm{RM}}$ phenotype to levels markedly greater than the additive effects of either condition alone (Figure $1 \mathrm{~F}$ ). The $\mathrm{CD}{ }^{+} \mathrm{CD} 103^{+}$cells induced by hypoxia + TGF- $\beta 1$ expressed the highest levels of CD49a, PD- 1 , and CD101, compared with the majority populations in the $20 \% \mathrm{O}_{2}$ and $2 \% \mathrm{O}_{2}$ conditions $\left(\mathrm{CD} 69^{-} \mathrm{CD}^{-103}{ }^{-}\right.$and $\mathrm{CD}^{+} 9^{+} \mathrm{CD} 103^{-}$, respectively) (Figure $1 \mathrm{G}$ ).

In vitro induced $T_{R M}$ exhibit enrichment for endogenous human $T_{R M}$ gene signatures. Since differences in $\mathrm{T}_{\mathrm{RM}}$ marker expression among the $\mathrm{CD}^{-} \mathrm{CD}^{-} 3^{-}\left(20 \% \mathrm{O}_{2}\right), \mathrm{CD}^{-} 9^{+} \mathrm{CD} 103^{-}\left(2 \% \mathrm{O}_{2}\right)$, and $\mathrm{CD}^{+} 9^{+} \mathrm{CD} 103^{+}\left(2 \% \mathrm{O}_{2}+\right.$ TGF- $\beta 1$ ) cells suggested that these represent distinct populations, each was sorted and transcriptionally profiled via RNA sequencing (RNA-Seq). Principal component analysis (PCA) confirmed that these 3 populations were distinct (Figure 2A). Hierarchical clustering showed distinct gene signatures for $\mathrm{CD}^{-} 9^{-} \mathrm{CD}^{-103^{-}}$and $\mathrm{CD} 9^{+} \mathrm{CD} 103^{+}$cells, whereas $\mathrm{CD} 69^{+} \mathrm{CD} 103^{-}$cells had a somewhat intermediate transcriptional profile (Figure 2, B and C). Comparison of the top DEGs between $\mathrm{CD}^{+} 9^{+} \mathrm{CD} 103^{+}$and $\mathrm{CD} 69^{-} \mathrm{CD} 103^{-}$cells revealed gene expression patterns consistent with those reported for endogenous human $\mathrm{T}_{\mathrm{RM}}$, including increased expression of ITGAE, EGR2, granulysin (GNLY), interleukin 2 receptor subunit $\beta$ (IL2RB), Bc12 modifying factor $(B M F)$, RasGEF domain family member 1B (RASGEF1B), and nuclear receptor subfamily 4 group A member $1(N R 4 A 1)$, and decreased expression of $S E L L, K L F 2$, and $K L F 3$, indicating a non-recirculating transcriptional program (Figure 2C; Supplemental Table 1; and refs. 22, 23, 32). S1PR1, a KLF2 target gene, was downregulated 1.5-fold ( $P$ adj $<0.05$ ), but this did not meet our fold change threshold. $\mathrm{CD} 69^{+} \mathrm{CD} 103^{+}$cells demonstrated increased expression of ITGA1, PDCD1, CD101, and TNFRSF9, all of which are consistently reported as upregulated in endogenous human $\mathrm{T}_{\mathrm{RM}}(22,23,26,33)$. We also observed elevated transcripts encoding the transcription factor NOTCH1, which is known to contribute to maintenance of lung $\mathrm{T}_{\mathrm{RM}}$, and $R B P J$, which is central to Notch signaling (Figure $2 \mathrm{C}$ and refs. 23, 34).

$\mathrm{T}_{\mathrm{RM}}$ often express various chemokines, perhaps as part of their "alarm function," to recruit immune cells to local tissues (35). Consistent with the endogenous $\mathrm{T}_{\mathrm{RM}}$ profile, $\mathrm{i}-\mathrm{T}_{\mathrm{RM}}$ upregulated CXCL13 and CCL20, as well as CCL4, CCL5, and CCL22 (Figure 2C; Supplemental Table 1; and refs. 22, 23, 26). Changes in expression of genes that have currently undefined roles but are consistently reported in endogenous human $\mathrm{T}_{\mathrm{RM}}$ were also observed, such as upregulation of MYO7A and RGS1 and downregulation of SERPINE2, RAP1GAP2, and RASGRP2 (Supplemental Table 1 and refs. 22, 23, 26).

To gain insight into the physiological relevance of our findings, we performed gene set enrichment analysis (GSEA) using gene signatures from published data sets of endogenous human $\mathrm{CD} 103^{+} \mathrm{T}_{\mathrm{RM}}$ compared with $\mathrm{CD}_{103^{-}}$effector memory $\mathrm{T}$ cells $\left(\mathrm{T}_{\mathrm{EM}}\right)$ from peripheral blood $(23,36)$. We observed that the transcriptional profile of $\mathrm{CD} 9^{+} \mathrm{CD} 103^{+}$cells versus $\mathrm{CD} 69^{-} \mathrm{CD} 103^{-}$cells was similar to those of $\mathrm{T}_{\mathrm{RM}}$ from human skin (Cheuk et al., ref. 36) and lung (Hombrink et al., ref. 23) tissues versus blood $\mathrm{T}_{\mathrm{EM}}$ (Figure 3A). Signatures of genes upregulated in $\mathrm{T}_{\mathrm{RM}}$ were more enriched, reflecting that increases in gene expression predominated the transcriptional differences between $\mathrm{CD}^{2} 9^{+} \mathrm{CD} 103^{+}$and $\mathrm{CD} 69^{-} \mathrm{CD} 103^{-}$cells, with enrichment driven by genes such as ITGAE, ITGA1, EGR2, BMF, PERP, CCL20, NOTCH1, RBPJ, and DUSP4, among others (Figure 2B, Figure 3A, and Supplemental Table 2). Analysis of these data sets for overlap revealed that all 3 shared genes related to TGF- $\beta$, cell adhesion, motility, and migration and genes encoding regulators of T cell differentiation: EGR2 and NR3C1 (glucocorticoid receptor, Figure 3B, and refs. 37, 38). Importantly, $\mathrm{NR} 3 \mathrm{C} 1$ has previously been shown to promote the formation of memory precursor $\mathrm{T}$ cells and can be upregulated by hypoxia $(38,39)$. In addition, there was considerable overlap between the transcriptional profiles of our $\mathrm{i}-\mathrm{T}_{\mathrm{RM}}$ and human skin $\mathrm{T}_{\mathrm{RM}}$, including a number of canonical hypoxia-responsive genes (e.g., $L D H A, M M P 9, C A 9$ ), as well as $L G A L S 3$, a newly identified marker of human skin $\mathrm{T}_{\mathrm{RM}}$ (40).

Multiple recent profiles of TILs in various solid tumor types have reported the presence of CD103+ $\mathrm{TIL}_{\mathrm{RM}}$ (41-45). Therefore, we compared $\mathrm{CD} 69^{+} \mathrm{CD} 103^{+}$cells (hypoxia + TGF- $\beta 1$ ) with $\mathrm{CD} 69^{+} \mathrm{CD} 103^{-}$ cells (hypoxia alone) or CD69-CD103- cells (normal culture conditions) and observed enrichment of the $\mathrm{CD}^{+} \mathrm{CD} 69^{+} \mathrm{CD} 103^{+}$human breast cancer TIL signature reported by Savas et al. (Figure 3A, Supplemental Figure 3, and ref. 41). As hypoxia and TGF- $\beta$ are common features of the tumor microenvironment (TME), our results suggest they may contribute to CD103+ TIL generation in vivo. Additionally, our results may help explain recent observations that $\mathrm{TIL}_{\mathrm{RM}}$ are more radioresistant, as hypoxia and TGF- $\beta$ are known to contribute to radioresistance, and DEGs in radioresistant human skin $\mathrm{T}_{\mathrm{RM}}$ show enrichment in the hypoxia pathway, relative to tissue-infiltrating $\mathrm{T}$ cells $(40,46-48)$. 
A

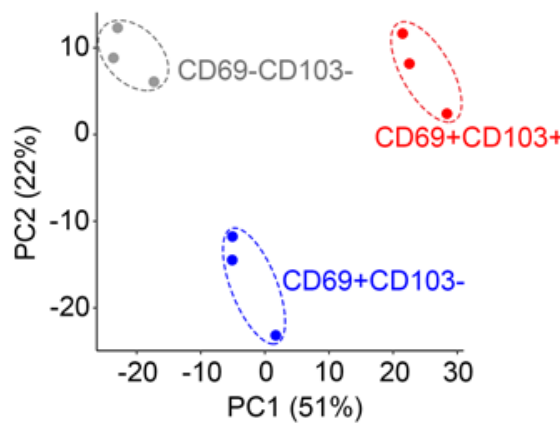

B

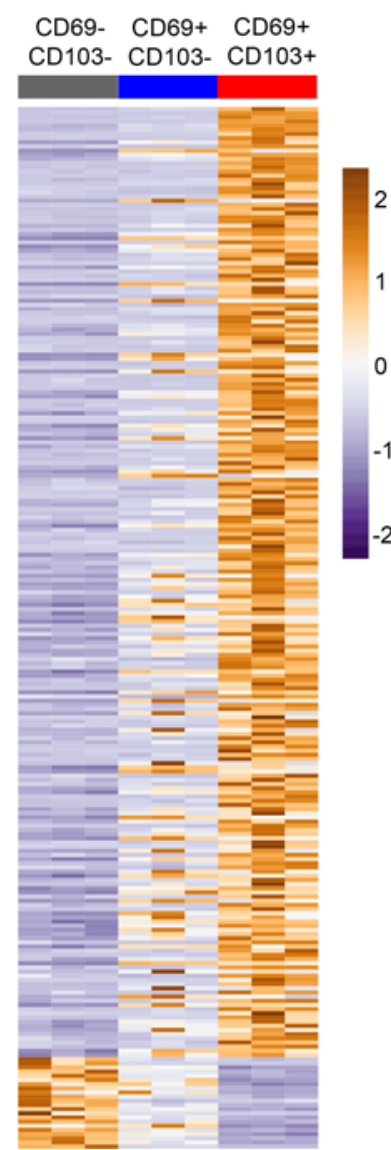

C
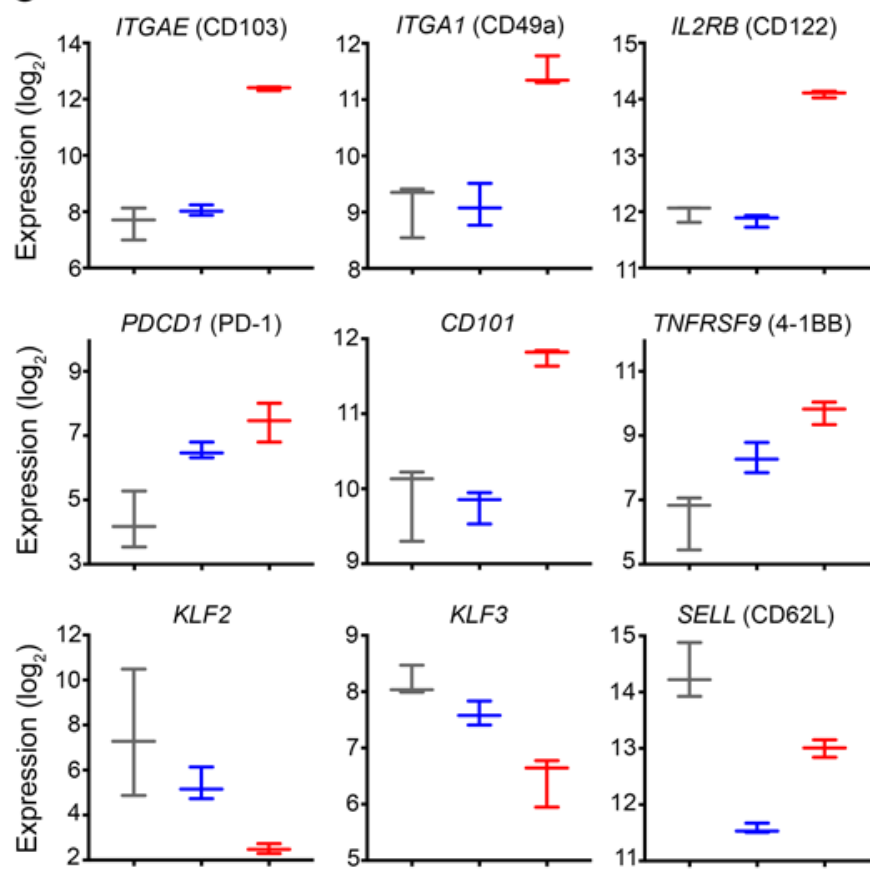

SELL (CD62L)
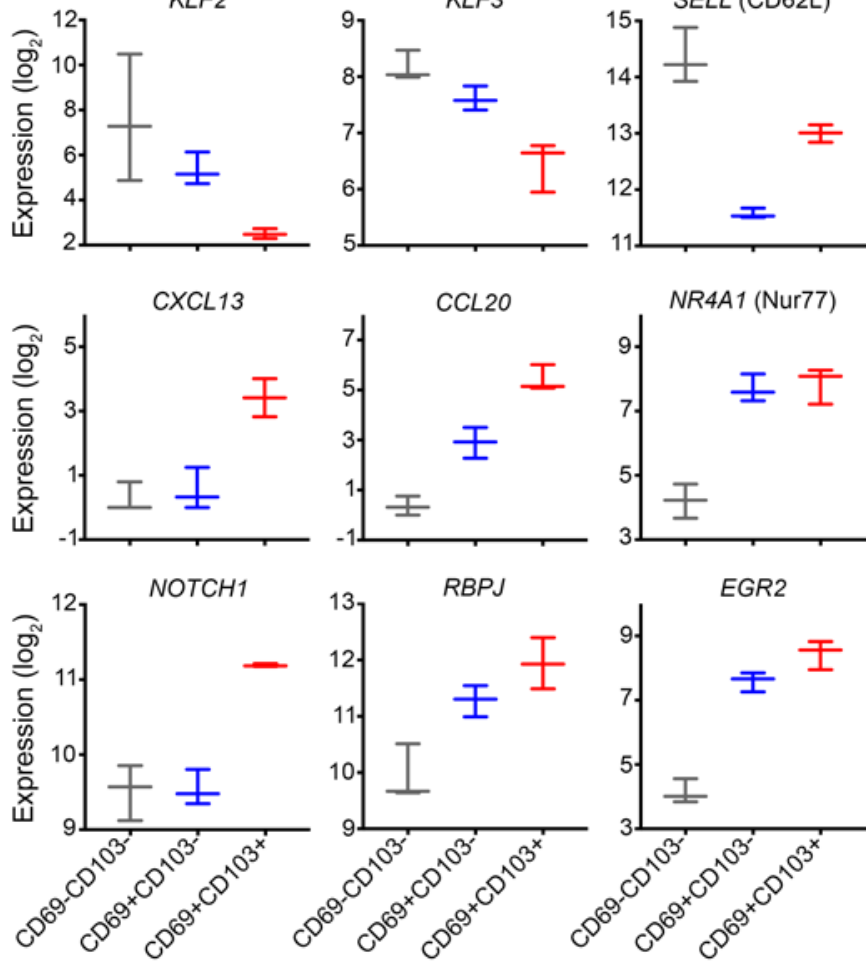

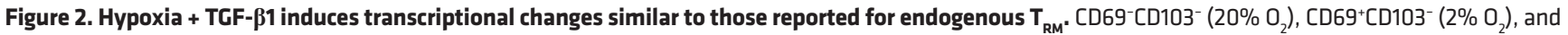
$\mathrm{CD} 69^{+} \mathrm{CD}_{103}{ }^{+}\left(2 \% \mathrm{O}_{2}+\mathrm{TCF}_{-} \beta 1\right) \mathrm{CD}^{+} \mathrm{T}$ cells were generated as described earlier and sorted before RNA isolation and transcriptome analysis via RNA sequencing (RNA-Seq) $(n=3)$. (A) Principal component analysis (PCA) of paired CD69-CD103-, CD69+CD103-', and CD69+CD103+ CD8 ${ }^{+}$T cells based on the global transcriptome. (B) Heatmap showing the top 250 differentially expressed genes (DEGs) for CD69-CD103- (gray), CD69+CD103- (blue), and CD69+CD103+ (red) cells generated in $20 \% \mathrm{O}_{2}, 2 \% \mathrm{O}_{2}$, and $2 \% \mathrm{O}_{2}+$ TGF- $\beta 1$, respectively. Legend represents $\mathrm{z}$ score, orange color indicates upregulation and purple color indicates downregulation. Differential expression determined by $\left|\log _{2} \mathrm{FC}\right| \geq 1$ and FDR $<0.05$. (C) Normalized expression levels of selected differentially expressed $\mathrm{T}_{\mathrm{RM}}$-associated genes, showing min, median, and max. TNFRSF9, 4-1BB; RBPJ, recombination signal binding protein for immunoglobulin kappa J region; ECR2, early growth response 2.

Since the immunosuppressive TME tends to drive $\mathrm{T}$ cells toward exhaustion, it is possible that cells differentiated in hypoxia + TGF- $\beta 1$ could become exhausted. Despite reports that hypoxia and TGF- $\beta 1$ can cause $\mathrm{T}$ cell exhaustion, we did not observe differential expression of the exhaustion-associated genes ENTPD1 (CD39), HAVCR2 (TIM3), LAG3, CTLA4, CD38, SLAMF6, CD244, TIGIT, and TOX (Supplemental Table 1 and refs. 49, 50). To further compare our i- $\mathrm{T}_{\mathrm{RM}}$ with exhausted $\mathrm{T}$ cells, we performed GSEA using published human $\mathrm{T}$ cell exhaustion signatures. The Quigley et al. signature showed an inverse enrichment pattern; that is, genes that are downregulated in exhausted $\mathrm{T}$ cells were upregulated (positively enriched) in our i- $\mathrm{T}_{\mathrm{RM}}$ (Supplemental Figure $4 \mathrm{~A}$ and ref. 51). Genes that are upregulated in exhausted $\mathrm{T}$ cells showed a trend toward negative 
A

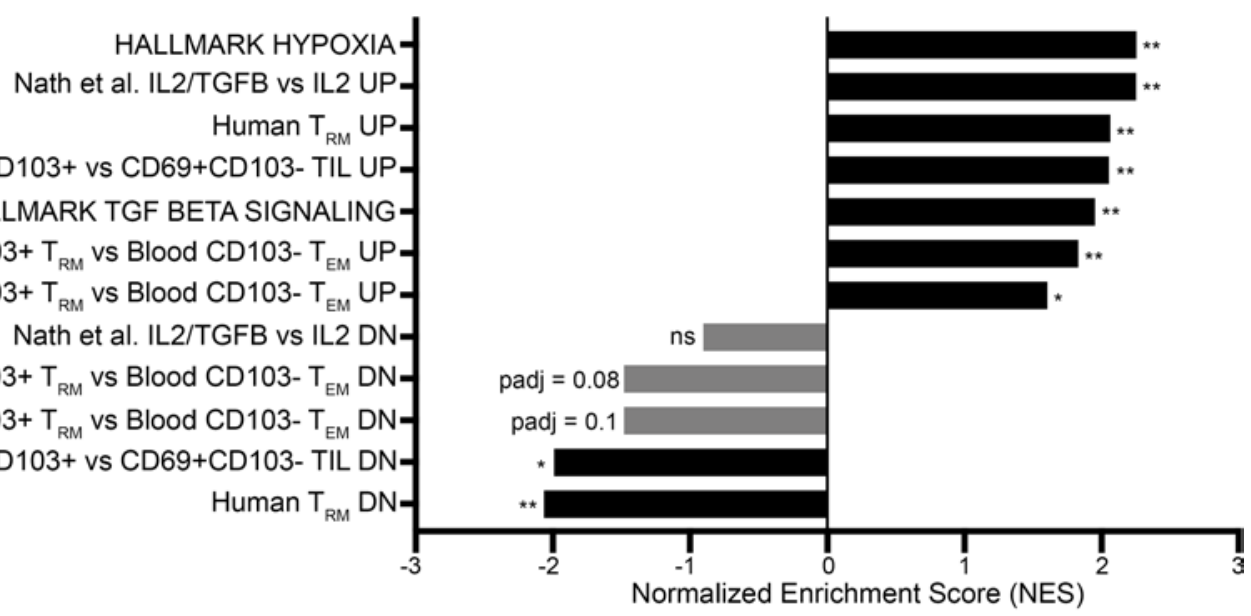

B

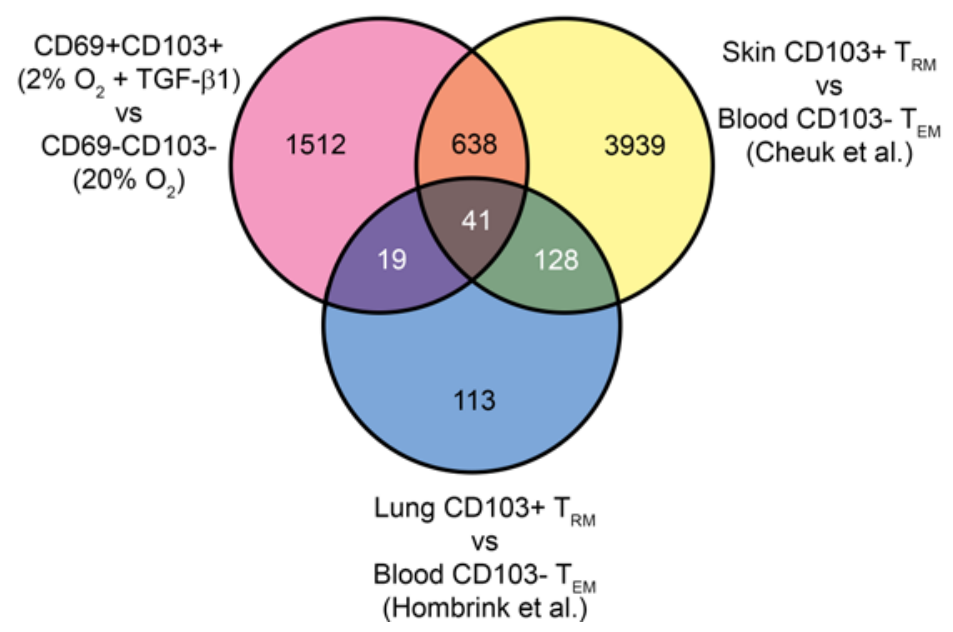

Figure 3. The hypoxia + TCF- $\beta 1 \mathrm{i}-\mathrm{T}_{\mathrm{RM}}$ transcriptional profile is enriched for endogenous human $\mathrm{T}_{\mathrm{RM}}$ gene signatures. $\mathrm{CD}^{-} \mathrm{9}^{-} \mathrm{CD} 103^{-}\left(20 \% \mathrm{O}_{2}\right), \mathrm{CD}^{-} 9^{+} \mathrm{CD} 103^{-}\left(2 \% \mathrm{O}_{2}\right)$, and $\mathrm{CD}_{69}{ }^{+} \mathrm{CD}_{103}{ }^{+}\left(2 \% \mathrm{O}_{2}+\mathrm{TCF}-\beta 1\right) \mathrm{CD} 8^{+} \mathrm{T}$ cells were generated as described earlier and sorted before RNA isolation and transcriptome analysis via RNA-Seq ( $n=$ 3). (A) CSEA of relevant gene signatures derived from endogenous $T_{R M}$ and resident memory-like tumor-infiltrating lymphocytes ( $\mathrm{TIL}_{\mathrm{RM}}$ ) in the transcriptome of $\mathrm{CD} 69^{+} \mathrm{CD}_{103}{ }^{+}$versus $\mathrm{CD69}^{-} \mathrm{CD103}^{-}$, presented as normalized enrichment score (NES), ${ }^{*} P$ adj $<0.05,{ }^{* *} P$ adj $<0.01$. (B) Venn diagram showing the overlap of DEGs

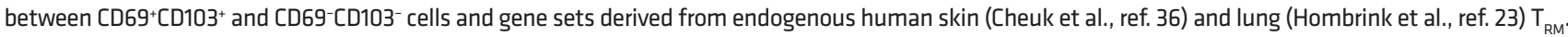

enrichment in our data set but did not reach statistical significance. The CD39+ exhaustion signature of upregulated genes (Gupta et al.) was enriched in our data set; however, aside from $P D C D 1$, the shared genes driving enrichment were not associated with exhaustion and instead encoded transcription factors and enzymes spanning a broad array of biological functions (Supplemental Table 2 and ref. 52). In comparison, genes upregulated in $T_{R M}$ from the skin of healthy individuals (Cheuk et al.) were more enriched in our data set, in terms of both significance and proportion (Supplemental Figure 4B and ref. 36). These data show that, compared with cells from normal cell culture conditions, $\mathrm{i}-\mathrm{T}_{\mathrm{RM}}$ do not exhibit an exhausted transcriptional profile.

Pathway analysis reveals biological commonalities between in vitro induced $T_{R M}$ and endogenous human $T_{R M}$. Ingenuity Pathway Analysis (IPA; QIAGEN) comparing $\mathrm{CD} 69^{+} \mathrm{CD} 103^{+}$cells with $\mathrm{CD} 69^{-} \mathrm{CD} 103^{-}$cells revealed that many of the DEGs were in the glycolysis and gluconeogenesis pathways (Figure 4). Given that hypoxia is a major regulator of cellular metabolism, these results were expected. There was also an enrichment of genes in the Notch signaling pathway, which has been reported in human lung $\mathrm{T}_{\mathrm{RM}}$ (23). To better understand the functional relevance of the hypoxia + TGF- $\beta$-induced $T_{R M}$ transcriptional profile, we ran pathway analysis on the Cheuk et al. data set and found that many of the same biological pathways were differentially regulated. Mirroring our earlier overlap analysis, we observed enrichment of DEGs in the HIF-1 $\alpha$ and TGF- $\beta$ signaling pathways in both transcriptional profiles (Figure 4). Changes in leukocyte extravasation signaling, agranulocyte adhesion and diapedesis, epithelial adherens junction signaling, and integrin signaling pathways, all involved in focal adhesion and related to changes in migratory programming, were common 
CD69+CD103+ vs CD69-CD103-

Cheuk et al. Skin CD103+ $T_{R M}$ vs Blood CD103- $T_{\text {EM }}$

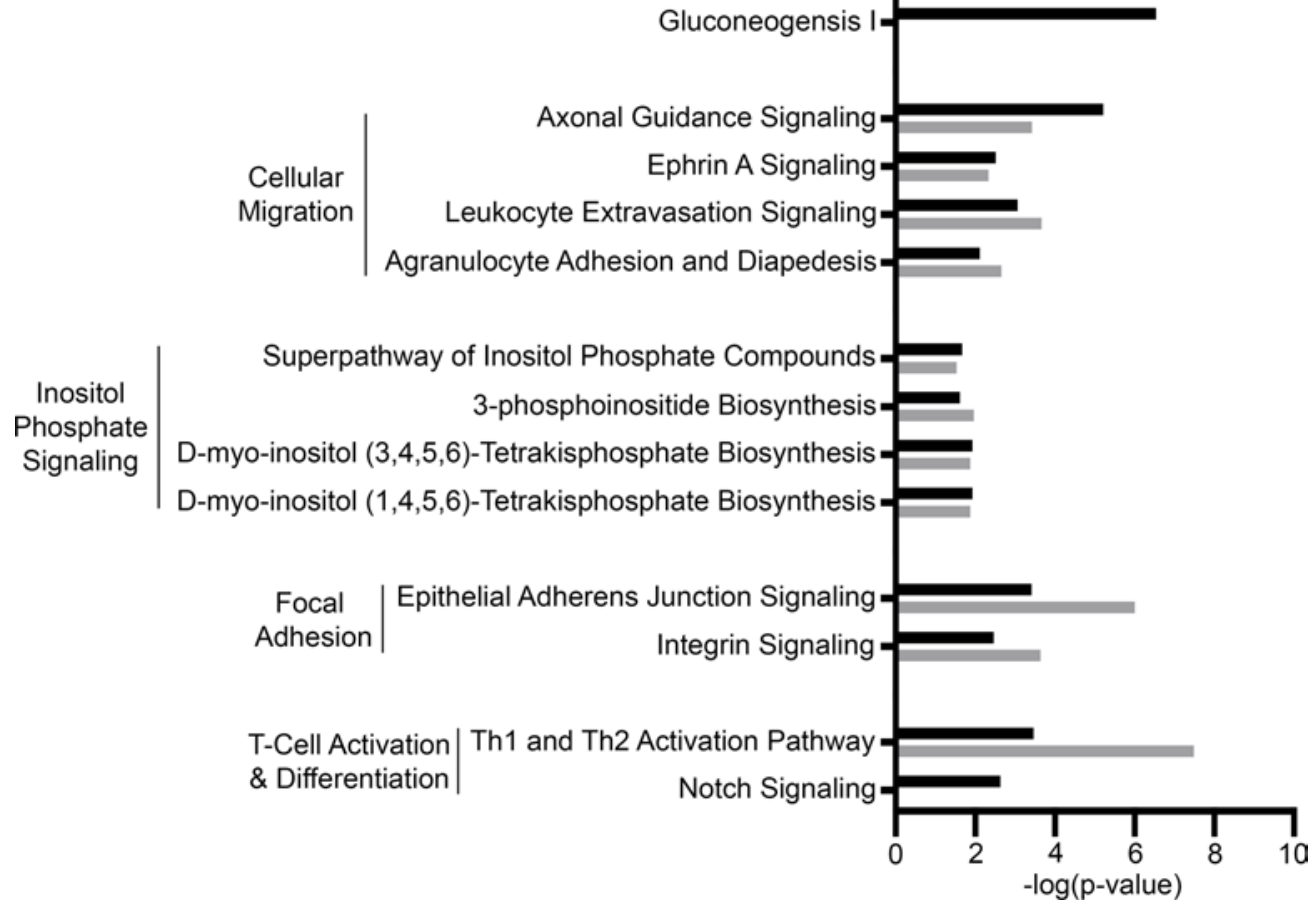

Figure 4. Pathways involved in metabolism, migration, and $\mathrm{T}_{\mathrm{PM}}$ generation and maintenance are differentially regulated in hypoxia + TCF- $\beta 1$ i-T $T_{R M}$. Differentially regulated IPA canonical pathways in hypoxia + TCF- $\beta 1$ i $-T_{R M}$ relative to their expression in $\mathrm{CD}^{-} \mathrm{CD}^{-} 103^{-}$cells and endogenous human skin $\mathrm{T}_{\mathrm{RM}}$ relative to blood $\mathrm{T}_{\mathrm{EM}}$ (Cheuk et al., ref. 36), shown with negative-log-transformed $P$ values. HIF-1 $\alpha$, hypoxia-inducible factor $1 \alpha$.

to their endogenous $\mathrm{T}_{\mathrm{RM}}$ and our $\mathrm{i}-\mathrm{T}_{\mathrm{RM}}$. Multiple pathways involved in inositol phosphate signaling were also enriched, in agreement with a previous report that PI3K signaling is implicated in cytokine-induced downregulation of KLF2 and may play a role in generation of $\mathrm{T}_{\mathrm{RM}}$ in vivo (10). Remarkably, the axonal guidance pathway was also differentially regulated in both analyses. Axonal guidance, while at first seemingly unrelated to $\mathrm{T}_{\mathrm{RM}}$ and unreported in current $\mathrm{T}_{\mathrm{RM}}$ literature, is a process whereby environmental cues influence cell migratory patterns (53). Many of the same factors governing axon guidance are also known to regulate immune cell trafficking and can be regulated by hypoxia and/or TGF- $\beta$ (53-59). Overall, these results show that our $\mathrm{i}-\mathrm{T}_{\mathrm{RM}}$ display striking similarities to endogenous human $\mathrm{T}_{\mathrm{RM}}$ at the biological pathway level.

In vitro induced $T_{R M}$ maintain their phenotype in response to milieu. To assess the stability of our $\mathrm{i}-\mathrm{T}_{\mathrm{RM}}$ phenotype, we sorted $\mathrm{CD} 69^{+} \mathrm{CD} 103^{+}$cells generated using hypoxia + TGF- $\beta 1$ and cultured them in parallel in $20 \%$ $\mathrm{O}_{2}$ or $2 \% \mathrm{O}_{2}$, with IL-2 or IL-15, and with or without TGF- $\beta$. After 48 hours of culture at $20 \% \mathrm{O}_{2}$ with IL-2 and without TGF- $\beta 1$, a slight majority of cells had lost CD69 expression (becoming CD69-CD103+) with a gradual decrease in CD49a expression; however, culture in hypoxia helped maintain CD69 expression, consistent with our earlier results (Figure 5). Culture with IL-2 and TGF- $\beta 1$ at both oxygen levels seemed to drive the cells toward CD103 single positivity but also helped maintain CD49a expression. In contrast, culture with IL-15 enabled maintenance of CD69 expression that was further enhanced in hypoxia, although CD49a expression declined. Culture in hypoxia with IL-15 and TGF- $\beta 1$ maintained expression of CD69, CD103, and CD49a in the majority of cells. IL-2 is the prototypical cytokine for effector T cell culture, whereas IL-15 is important for the maintenance of memory $\mathrm{T}$ cells and the development and/or maintenance of $\mathrm{T}_{\mathrm{RM}}$ in several organs $(2,24,60-62)$. The dependence of our $\mathrm{i}-\mathrm{T}_{\mathrm{RM}}$ on IL-15 may be related to their increased expression of $I L 2 R B$, which encodes the $\beta$ chain of the IL-15 receptor (CD122), in line with murine studies on the importance of IL-15 responsiveness for skin $\mathrm{T}_{\mathrm{RM}}(3,62)$. Further, it has been shown that exposure of human PBMCs to IL- 15 and TGF- $\beta 1$ can also induce a CD69 ${ }^{+} \mathrm{CD} 103^{+}$phenotype in $\mathrm{CD} 8^{+}$ 


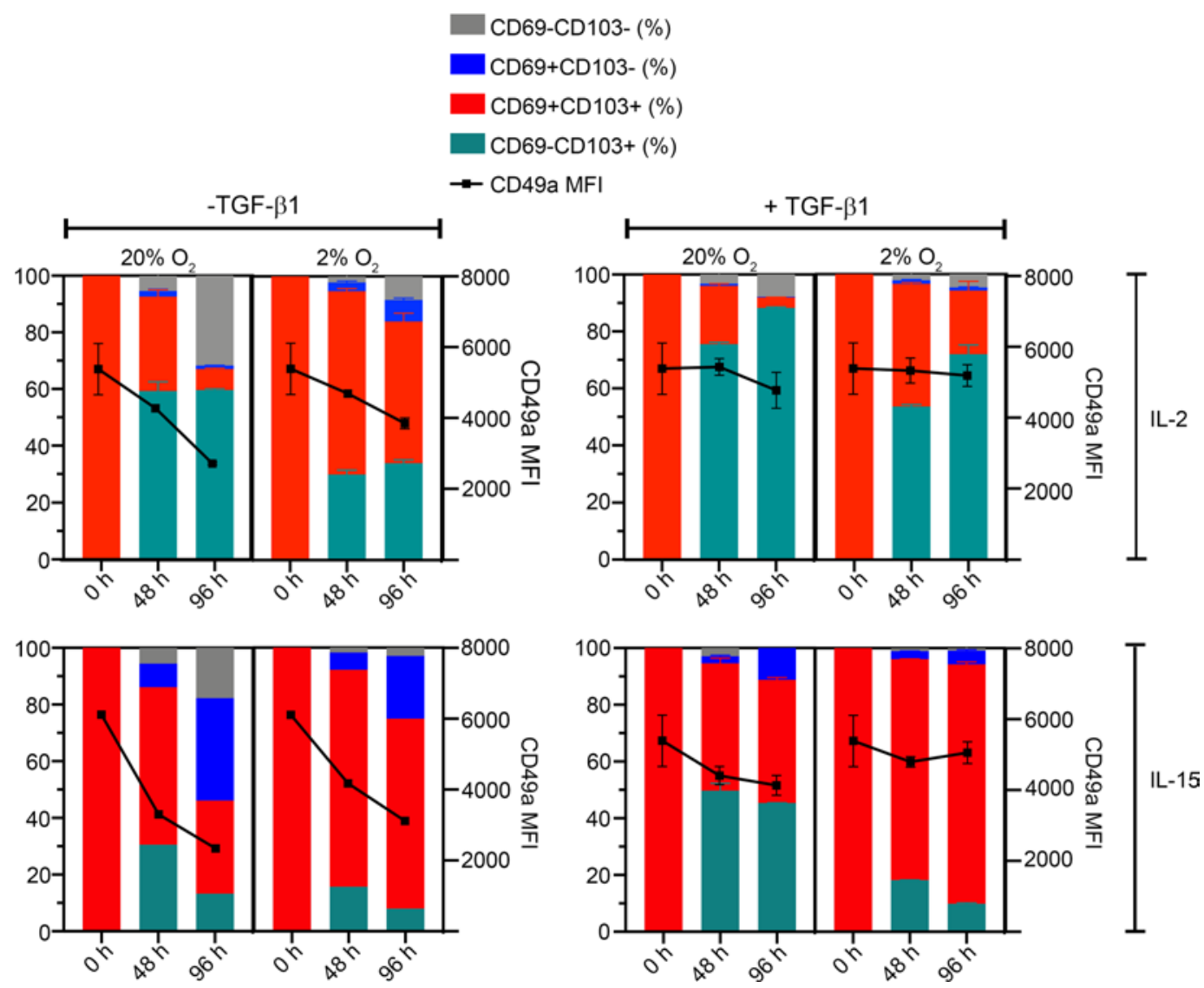

Figure 5. In vitro induced $T_{R M}$ maintain their phenotype in response to environmental cues. $C D 69^{+} C D 103^{+} C D 8^{+} T$ cells were generated in $2 \% \mathrm{O}_{2}+\mathrm{TCF}-\beta 1$ as described earlier, sorted, and distributed into parallel cultures in $20 \% \mathrm{O}_{2}$ or $2 \% \mathrm{O}_{2}$ in the presence of IL-2 or IL-15, with or without TGF- $\beta 1$. Cells were analyzed for expression of $\mathrm{T}_{\mathrm{RM}}$-associated markers via flow cytometry at 0 hours, 48 hours, and 96 hours (indicated along the $x$ axis). Data are from 2 independent donors $(n=2)$ and 2 independent experiments, excepting the IL-15 without TCF- $\beta 1$ condition $(n=1)$; mean \pm SEM shown.

T cells (8). Thus, these data demonstrate that in addition to TGF- $\beta 1$, hypoxia can cooperate with other environmental cues, such as IL-15, to promote a $\mathrm{T}_{\mathrm{RM}}$ phenotype in $\mathrm{T}$ cells. Our results also indicate that maintenance of the $\mathrm{i}-\mathrm{T}_{\mathrm{RM}}$ phenotype relies on environmental cues, mirroring the plasticity and environmental adaptability of endogenous (murine) $\mathrm{T}_{\mathrm{RM}}$, which can alter their phenotype but reacquire $\mathrm{T}_{\mathrm{RM}}$ characteristics when exposed to the appropriate milieu $(63,64)$.

Hypoxia and TGF- $\beta 1$ influence the human $T_{R M}$ differentiation program. We showed earlier that hypoxia or TGF- $\beta 1$ alone can generate $\mathrm{CD} 69^{+} \mathrm{CD} 103^{+}$cells, but their combination results in the greatest induction (Figure $1 \mathrm{~F}$ ). This observation raised the question of whether $\mathrm{CD} 69^{+} \mathrm{CD} 013+$ cells from the combination condition are simply greater in number or actually phenotypically distinct. Comparison of $T_{R M}$ core signature protein expression via flow cytometry indicated that $\mathrm{CD} 69^{+} \mathrm{CD} 103^{+}$populations from the different conditions are not identical. Consistent with previous results, $\mathrm{CD} 69^{+} \mathrm{CD} 103^{+}$cells generated in hypoxia displayed higher CD69 expression, and those that were exposed to TGF- $\beta 1$ were marked by higher CD103 expression (Figure 6A). TGF- $\beta 1$ exposure was also related to higher expression of PD-1 and CD101. Remarkably, hypoxia alone induced elevated CD103 and CD49a expression; however, the combination of hypoxia and TGF- $\beta 1$ resulted in $\mathrm{CD}_{69}{ }^{+} \mathrm{CD} 103^{+}$cells with the highest levels of CD103 and CD49a expression (Figure 6A). While the influence of TGF- $\beta 1$ on CD103 and CD49a has been reported, to our knowledge, this is the first implication of hypoxia in induction of these canonical $\mathrm{T}_{\mathrm{RM}}$-associated integrins $(5,30,31,65)$. These observations also further support our findings that hypoxia and TGF- $\beta 1$ are synergistic cues for $\mathrm{T}_{\mathrm{RM}}$ phenotype acquisition.

To compare the populations at the transcriptional level, we sorted $\mathrm{CD} 69^{+} \mathrm{CD} 103^{+}$cells generated by hypoxia alone $\left(2 \% \mathrm{O}_{2}\right)$, TGF- $\beta 1$ alone $\left(20 \% \mathrm{O}_{2}+\right.$ TGF- $\left.\beta 1\right)$, and their combination $\left(2 \% \mathrm{O}_{2}+\right.$ TGF- $\left.\beta 1\right)$ and conducted RNA-Seq. PCA showed that all 3 groups of $\mathrm{CD}^{2} 9^{+} \mathrm{CD} 103^{+}$cells clustered away from $\mathrm{CD} 69$ CD103- cells from normal cell culture conditions analyzed previously $\left(20 \% \mathrm{O}_{2}\right.$, batch1), indicating relative similarity (Figure 6B). All data were normalized and corrected for batch variation, and we validated that 

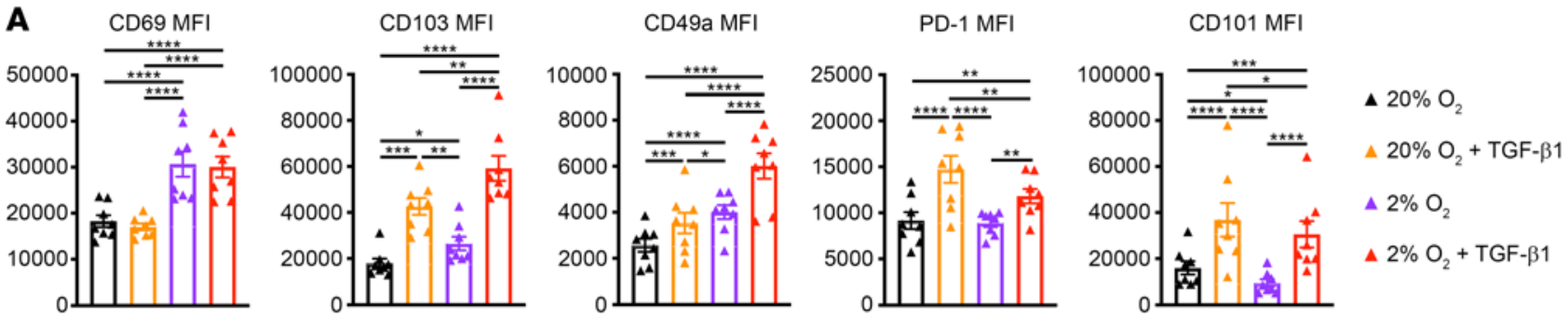

B

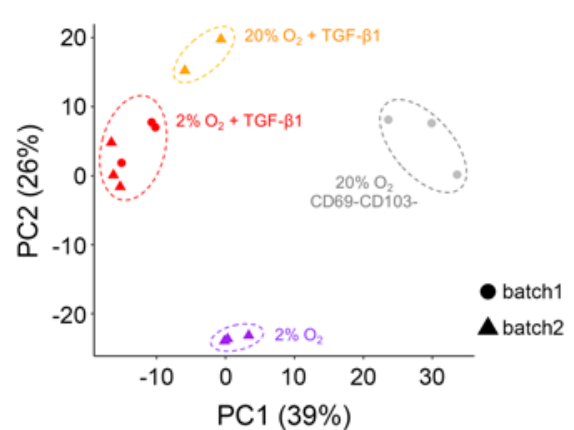

C

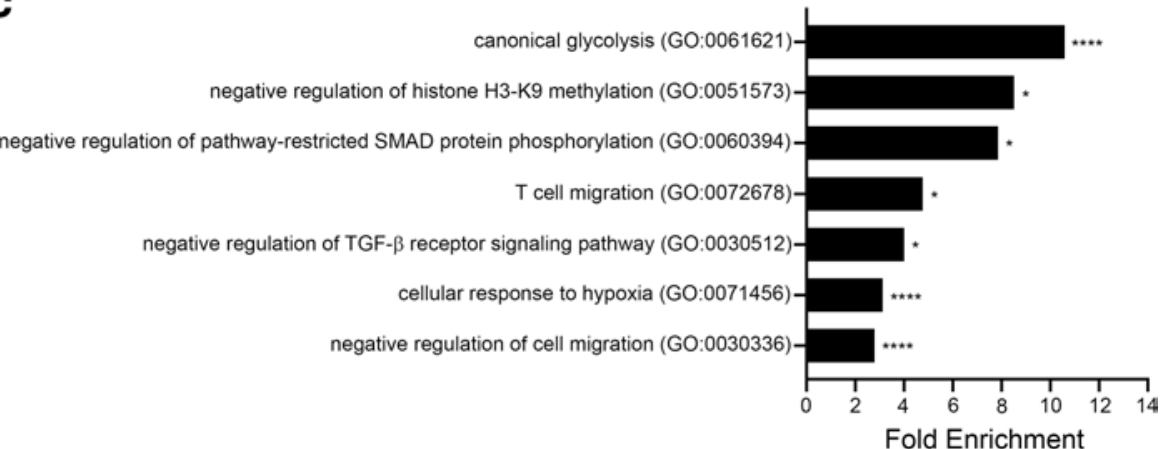

Figure 6. $\mathrm{CD}^{+} \mathbf{C D D 1 0 3}^{+}$cells generated in single and combination conditions are distinct. Naive CD8 ${ }^{+} \mathrm{T}$ cells were activated in $20 \% \mathrm{O}_{2}$ or $2 \% \mathrm{O}_{2}$ for 4 days and then for an additional 2 days with or without TGF- $\beta 1$. (A) Expression of $\mathrm{T}_{\mathrm{pm}}$-associated markers was assessed by flow cytometry, $n=8$. Two-way ANOVA, ${ }^{*} P$ adj $<0.05,{ }^{* *} P$ adj $<0.01,{ }^{* *} P$ adj $<0.001,{ }^{* * *} P$ adj $<0.0001$; data are mean \pm SEM. CD69+CD103 ${ }^{+}$cells generated in $20 \% \mathrm{O}_{2}+$ TCF- $\beta 1,2 \% \mathrm{O}_{2}$, or $2 \% \mathrm{O}_{2}+$ TCF- $\beta 1$ were sorted before isolation of RNA for analysis via mRNA sequencing $(n=2-3)$. (B) PCA of paired CD69 ${ }^{+}$CD103+ ${ }^{+}$cells from the different culture conditions (batch2) and CD69-CD103- cells from previous analysis (batch1). (C) Selected significantly overrepresented Gene Ontology (GO) terms with fold enrichment, ${ }^{*} P$ adj $<0.05,{ }^{* * *} P$ adj $<0.0001$.

this clustering pattern was not due to batch effects by including $\mathrm{CD} 69^{+} \mathrm{CD} 103^{+}$samples from our previous analysis (batch1), confirming that they clustered with the $2 \% \mathrm{O}_{2}+$ TGF- $\beta 1$ group samples as expected. Cells exposed to TGF- $\beta 1$ clustered closer to each other than to those cultured in hypoxia alone, suggesting that the effects of TGF- $\beta 1$ predominate in our system. Differential expression analysis was performed only among samples from the same batch (batch2) in order to analyze matched samples. Gene Ontology (GO) analysis on the 1014 DEGs between the 3 group conditions ( $P$ adj $<0.001$, determined by likelihood ratio test) revealed enrichment of genes involved in glycolysis and hypoxia response, regulation of TGF- $\beta$ signaling (TGF- $\beta$ receptor and SMADs), and cell migration (Figure 6C). Interestingly, genes encoding regulators of histone methylation were also enriched, suggesting an epigenetic component.

Closer examination of $\mathrm{T}_{\mathrm{RM}}$ signature genes revealed many that were primarily influenced by TGF- $\beta 1$, including ITGAE, CD101, KLF2, NOTCH1, and IL2RB (Figure 7A). ITGA1 transcript levels were also similar between TGF- $\beta 1$-treated groups, suggesting a posttranscriptional mechanism for the CD49a upregulation observed (Figure 6A and Figure 7A). Expression of CD69, S1PR1, SELL, and EGR3 was more heavily influenced by hypoxia, and CXCR4 and CCR5 transcript levels were highest only in $\mathrm{CD} 69^{+} \mathrm{CD} 103^{+}$cells from the combination condition (Figure 7A). Examination of the genes driving enrichment in the GO analysis showed that hypoxia exposure also influenced expression of genes encoding a number of adhesion molecules and epigenetic regulators, including upregulation of several histone lysine demethylases (KDMs): $K D M 5 B$, $K D M 4 C, K D M 4 B$, and $K D M 3 A$ (Figure 7B). Expression patterns of genes involved in hypoxia response and regulation of TGF- $\beta$ signaling provided some insight into the interaction of these 2 pathways. TGF- $\beta 1$ exposure upregulated HIF1A, which encodes the transcription factor HIF-1 $\alpha$, and downregulated several genes encoding negative regulators of HIF-1 $\alpha$ : EGLN1, EGLN3, and CITED2 $(66,67)$. Hypoxia exposure resulted in increased expression of BNIP3 and BNIP3L, which was slightly dampened by TGF- $\beta 1$ exposure. Apart from their roles in apoptosis, BNIP3 and BNIP3L also mediate autophagy, which is involved in generation and perhaps maintenance of memory $\mathrm{T}$ cells, such as human liver $\mathrm{T}_{\mathrm{RM}}$, and this is the function we propose, given our earlier observation that cellular viability is not compromised by hypoxia (68-70). Similarly, hypoxia increased expression of $S M A D 3$, which encodes an important TGF- $\beta$ signaling mediator, and decreased expression of several negative regulators of TGF- $\beta$ signaling ( $S M A D 7, S M U R F 1, S M U R F 2, S K I L)$. However, cells exposed 
A

$$
\begin{aligned}
& 2 \% \mathrm{O}_{2} \\
& 2 \% \mathrm{O}_{2}+\text { TGF- } \beta 1 \\
& 20 \% \mathrm{O}_{2}+\text { TGF- } \beta 1
\end{aligned}
$$

ITGAE (CD103)

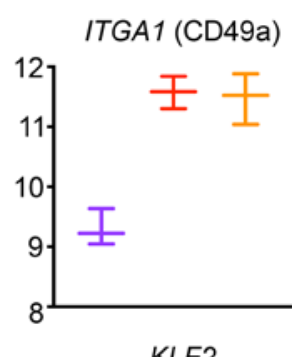

CD101
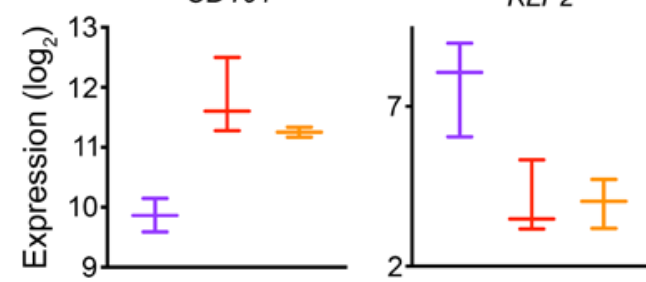

$\mathrm{NOTCH} 1$
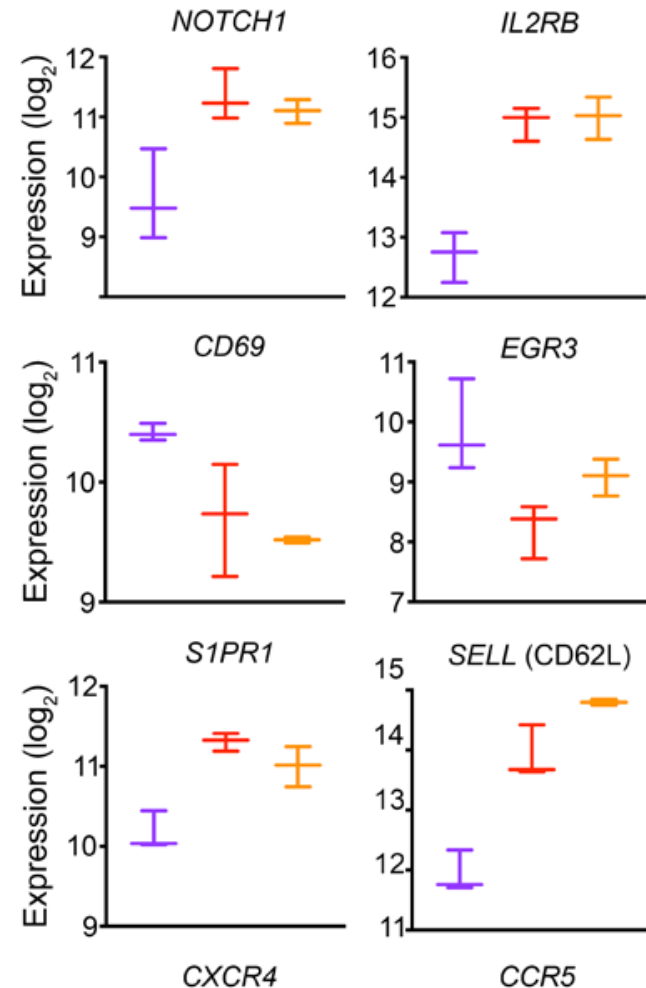

CXCR4

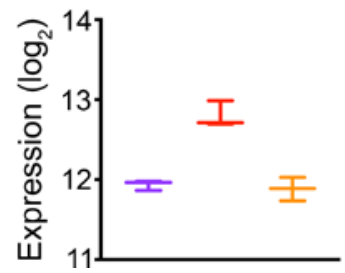

B Adhesion Molecules

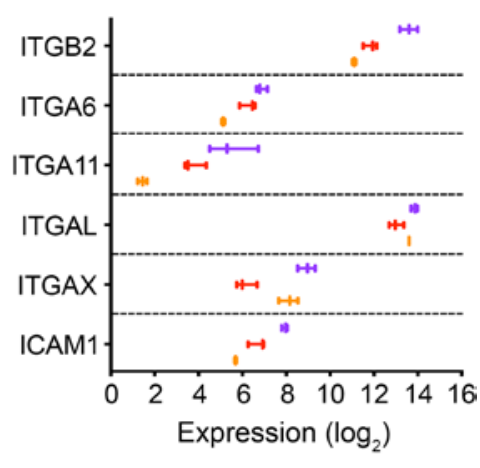

Epigenetic Regulators

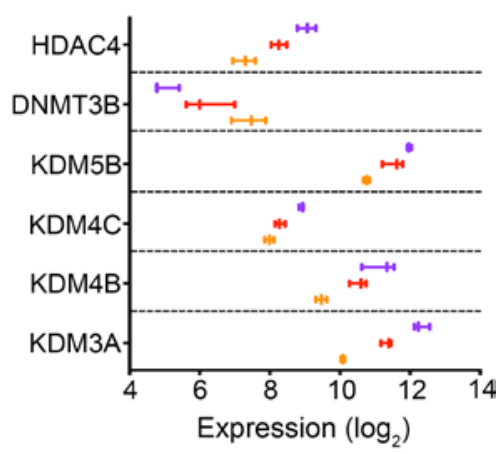

Hypoxia Response

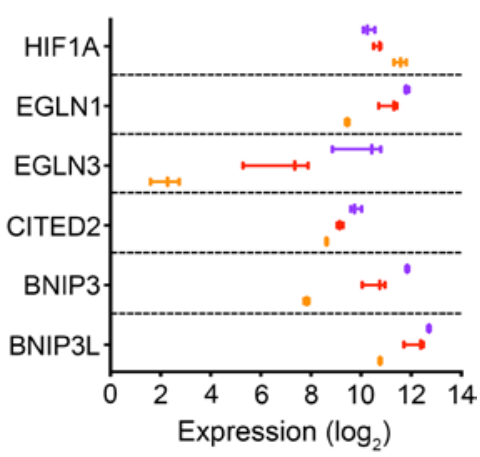

TGF- $\beta$ Regulation

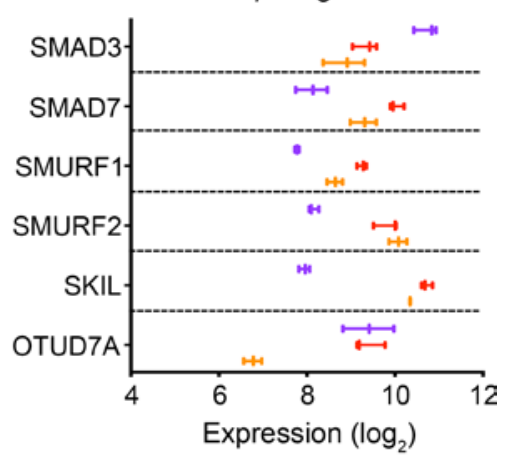

Figure 7. Transcriptional comparison of $\mathrm{CD} 6 \mathbf{9}^{+} \mathrm{CD}_{103}{ }^{+}$cells generated in single and combination conditions. $\mathrm{CD} 69+\mathrm{CD} 103^{+}$cells generated in $20 \% \mathrm{O}_{2}+$ TCF- $\beta 1,2 \% \mathrm{O}_{2}$, or $2 \% \mathrm{O}_{2}+$ TGF- $\beta 1$ were sorted before RNA isolation and analysis via mRNA sequencing $(n=2-3)$. (A) Normalized expression levels of selected differentially expressed $T_{P M}$-associated genes, showing min, median, and max. (B) Normalized expression levels of selected DEGs derived from $G 0$ terms in Figure 6C, grouped by category. Differential expression determined by likelihood ratio test and $P$ adj $<0.001$. EGLN1, egl-9 family hypoxia inducible factor 1; CITED2, Cbp/p300 interacting transactivator with Glu/Asp rich carboxy-terminal domain 2; BNIP3, BCL2 interacting protein 3; SMURF1, SMAD specific E3 ubiquitin protein ligase 1; SKIL, SKI like proto-oncogene. 
A

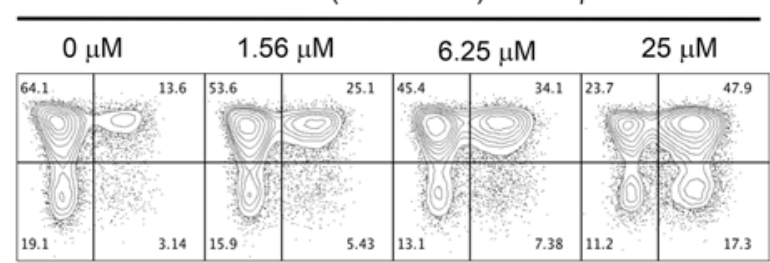

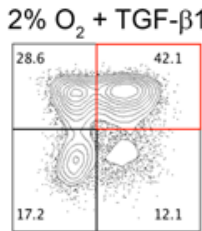
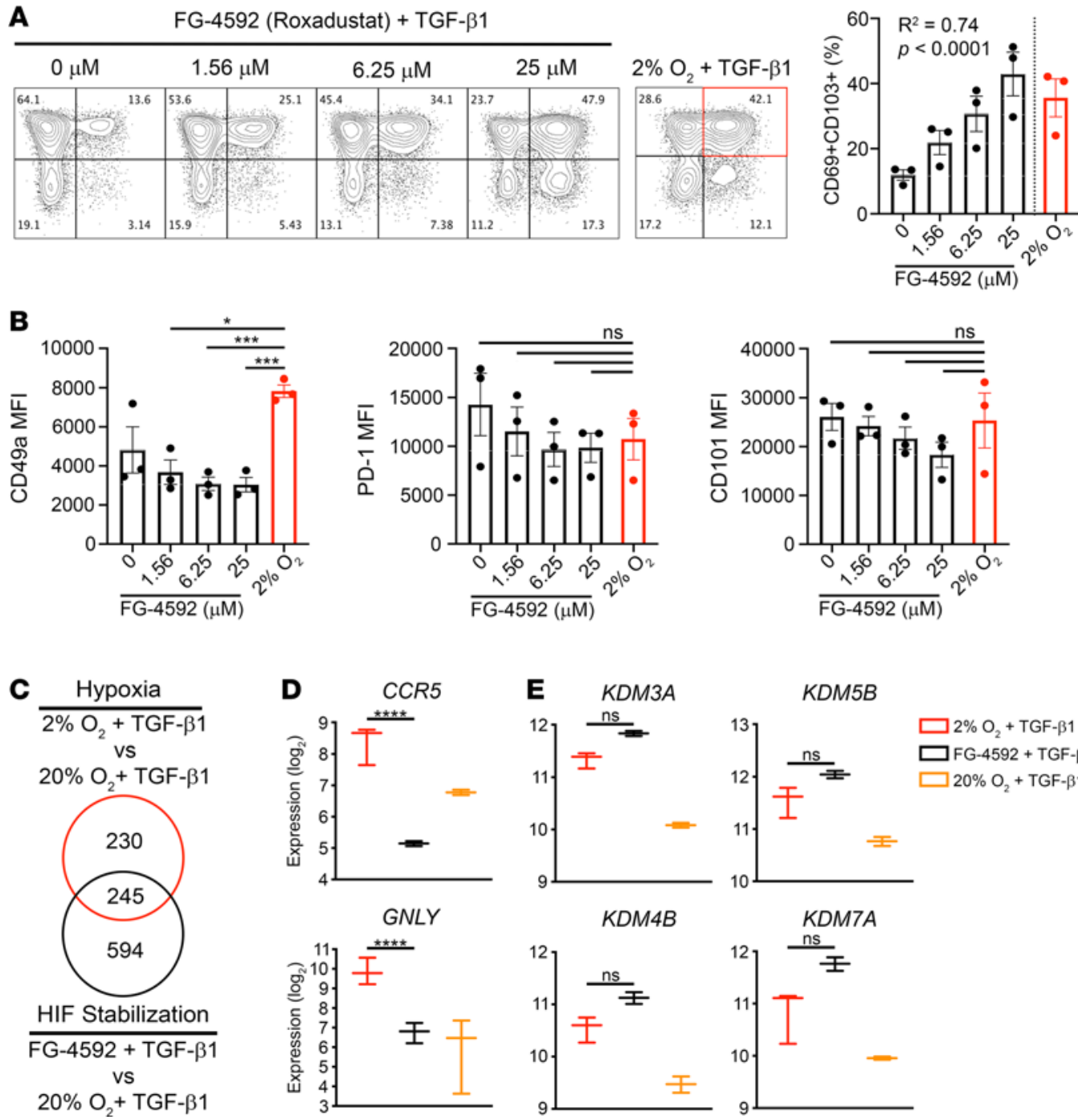

Figure 8. HIF stabilization partially reproduces hypoxia-induced $\mathrm{T}_{\mathrm{pM}}$ phenotype. Naive $\mathrm{CD} 8^{+} \mathrm{T}$ cells were activated in $20 \%$ $\mathrm{O}_{2}\left(\mathrm{Atmos}_{2}\right)$ in the presence of FG-4592 for 4 days and then for an additional 2 days with TGF- $\beta 1$. Cells activated in $2 \% \mathrm{O}_{2}$ with addition of TCF- $\beta 1$ on day 4 are shown in red for comparison. (A) Frequency of the CD69+CD103+ population and (B) expression of $\mathrm{T}_{\mathrm{RM}}$-associated markers by the $\mathrm{CD69}{ }^{+} \mathrm{CD} 103^{+}$population were assessed by flow cytometry, with representative results shown in $\mathbf{A}$ for 1 donor, $n=3$. Repeated measures 1-way ANOVA ( $\mathbf{A}$ and $\mathbf{B}$ ) followed by test for trend (A) or Dunnett's multiple comparisons test (B), ${ }^{*} P$ adj $<0.05,{ }^{* * *} P$ adj $<0.001$; data are mean \pm SEM. CD69+CD103 ${ }^{+}$cells generated in FG-4592 or $2 \% \mathrm{O}_{2}$, with addition of TGF- $\beta 1$ were sorted before RNA isolation and analysis via mRNA sequencing $(n=2-3)$, with differential expression determined by $\left|\log _{2} F C\right| \geq 1$ and FDR $<0.05$. (C) Venn diagram showing the overlap of DEGs between $\mathrm{CD}_{69}{ }^{+} \mathrm{CD}_{103}{ }^{+}$cells generated via FG-4592 or $2 \% \mathrm{O}_{2}$ relative to $20 \% \mathrm{O}_{2}$ (all with addition of TCF- $\beta 1$ ). (D) Normalized expression levels of selected DEGs between $\mathrm{CD} 69^{+} \mathrm{CD}_{103}{ }^{+}$cells generated in $\mathrm{FG}-4592$ or $2 \% \mathrm{O}_{2}$, showing min, median, and max; ${ }^{* * *} P$ adj $<0.0001$. CD69+CD103+ cells generated via TCF- $\beta 1$ alone $\left(20 \% \mathrm{O}_{2}\right)$ are shown for reference.

to hypoxia + TGF- $\beta$ had higher levels of SMAD7, SMURF1, and SKIL transcripts. These observations illustrate how hypoxia and TGF- $\beta$ might potentiate and attenuate each other's signaling and activity in a complex molecular network promoting the $\mathrm{T}_{\mathrm{RM}}$ differentiation program.

Hypoxia-induced $T_{R M}$ phenotype is partially recapitulated by HIF stabilization. HIFs are transcription factors governing the cellular response to hypoxia that are regulated by prolyl hydroxylase (PHD) enzymes, which require oxygen to function (71). To assess whether HIFs mediated the hypoxic induction of $\mathrm{CD} 69^{+} \mathrm{CD} 103^{+}$ cells, we used the HIF PHD inhibitor FG-4592 (roxadustat) to stabilize HIFs during differentiation experiments in $20 \% \mathrm{O}_{2}$ with the addition of TGF- $\beta 1$ (72). We observed a dose-dependent increase in CD69+ $\mathrm{CD} 103^{+}$ cells that reached frequencies similar to those in $2 \% \mathrm{O}_{2}+$ TGF- $\beta 1$ (Figure 8A). This increase was primarily driven by increased CD69 expression, consistent with a recent report showing CD69 is a HIF target gene (Supplemental Figure 5 and ref. 29). To further assess whether HIF stabilization by PHD inhibition 
reproduces the hypoxia-induced $\mathrm{T}_{\mathrm{RM}}$ phenotype, we compared expression of CD49a, PD-1, and CD101 on $\mathrm{CD} 9^{+} \mathrm{CD} 103^{+}$cells generated via both routes. Although the addition of FG-4592 slightly decreased CD49a, PD-1, and CD101 expression when compared with TGF- $\beta 1$ alone $(0 \mu \mathrm{M})$, PD-1 and CD101 expression levels were not significantly different from those of cells differentiated in hypoxia + TGF- $\beta 1$, suggesting that HIFs are involved in $\mathrm{T}_{\mathrm{RM}}$ phenotype acquisition (Figure $8 \mathrm{~B}$ ). HIF stabilization via PHD inhibition did not recapitulate CD49a expression; however, this may be due to off-target effects of FG-4592. PHDs also regulate collagen biosynthesis, and since CD49a is part of the collagen-binding complex very late antigen-1, its expression may be affected by PHD inhibition (73).

To gain insight into the contributions of hypoxia versus HIFs, we compared the transcriptional profiles of $\mathrm{CD} 9^{+} \mathrm{CD} 103^{+}$cells induced by $2 \% \mathrm{O}_{2}+$ TGF- $\beta 1$ or FG- $4592+$ TGF- $\beta 1$, using $\mathrm{CD} 69^{+} \mathrm{CD} 103^{+}$cells induced by TGF- $\beta 1$ alone as a common reference. While the DEGs did not completely overlap, there was considerable similarity (Figure $8 \mathrm{C}$ ). $\mathrm{T}_{\mathrm{RM}}$-associated genes generally were not among the DEGs, again likely owing to the dominant effect of TGF- $\beta 1$. Direct comparison of $\mathrm{CD}^{2} 9^{+} \mathrm{CD} 103^{+}$cells induced by hypoxia or FG-4592 showed there was no significant difference in their expression of core $\mathrm{T}_{\mathrm{RM}}$ signature genes; however, genes encoding CCR5 and GNLY were upregulated only by hypoxia (Figure 8D). Interestingly, genes encoding several of the KDMs discussed earlier were among the overlapping DEGs, and direct comparison of $\mathrm{CD} 69^{+} \mathrm{CD} 103^{+}$cells induced by hypoxia or FG-4592 revealed comparable expression; however, the activity of these enzymes may differ between the 2 conditions (Figure 8E). These KDMs belong to a class of enzymes known as 2-oxoglutarate-dependent oxygenases, which utilize oxygen in their functions and thus are also regulated by oxygen in a HIF-independent manner (74). As this is the same class of enzymes to which HIF PHDs belong, it is possible that their activity would be affected by FG-4592; however, this is unlikely at the doses used here (73). These demethylases vary in their targets and sensitivity to oxygen and chemical inhibitors, so specific changes in activity and their downstream consequences in this study are currently unclear. In light of the large degree of overlap in expression of $\mathrm{T}_{\mathrm{RM}}$-associated genes between the TGF- $\beta 1$-treated groups, it is plausible that alterations in chromatin accessibility are partially responsible for the increased frequency of $\mathrm{CD} 69^{+} \mathrm{CD} 103^{+}$cells in hypoxia and hypoxia-mimetic conditions. Indeed, recent work characterizing murine small intestine $\mathrm{T}_{\mathrm{RM}}$ differentiation reported high $K D M 5 B$ expression in a likely $\mathrm{T}_{\mathrm{RM}}$ precursor population, concordant with the early time point used in our study (75). Overall, these results suggest that HIFs are involved in $\mathrm{T}_{\mathrm{RM}}$ phenotype acquisition, with the possibility that HIF-independent effects of hypoxia may play a role as well.

\section{Discussion}

The well-documented heterogeneity among $\mathrm{T}_{\mathrm{RM}}$ is likely due to varying environments across tissue niches, and we propose that hypoxia is one of the many possible environmental cues for the $\mathrm{T}_{\mathrm{RM}}$ program $(6,28,32,33,36$, $63,76-78)$. The intestine, skin, and reproductive tract, sites with well-characterized $\mathrm{T}_{\mathrm{RM}}$ populations, are known to be relatively hypoxic (14-16). This is further reflected in our findings of similarity between hypoxia-cultured $\mathrm{i}-\mathrm{T}_{\mathrm{RM}}$ and human skin $\mathrm{T}_{\mathrm{RM}}$, due in part to the enrichment of hypoxia-responsive genes. However, questions may be raised regarding the relevance of hypoxia as an environmental cue in the lung, which, in addition to being an important site of $\mathrm{T}_{\mathrm{RM}}$ accumulation, is the organ responsible for oxygen exchange. Interestingly, a study on human lung $\mathrm{T}_{\mathrm{RM}}$ reported increased expression of transcripts encoding HIFs and enrichment of hypoxiainducible genes when compared with $\mathrm{T}$ cells from peripheral blood (23). These findings could be attributed to the sources of tissue samples used: patients with lung tumors or chronic obstructive pulmonary disease, which are both conditions that can create hypoxic environments (79-81). However, although oxygen levels in the alveoli are high, oxygen tensions in lung tissue can be comparable to those in other organs (median $\sim 5 \%$; refs. 80 , $82,83)$. A recent study comparing murine lung airway and interstitial $\mathrm{T}_{\mathrm{RM}}$ highlights how microenvironmental variation within the same organ can impact $\mathrm{T}_{\mathrm{RM}}$ heterogeneity (76). Varying degrees of vascularization create a range of oxygen levels within an organ, presumably making the epidermis more hypoxic than the dermis of the skin and the white pulp more hypoxic than the red pulp of the spleen $(12,13,84)$. Small $\mathrm{T}_{\mathrm{RM}}$ populations have also been described in secondary lymphoid organs (SLOs), which are predominantly sites of recirculation (26, 85). In this case microenvironmental hypoxia could promote $T_{R M}$ differentiation as a function of distance from blood vessels within the organ, or through inflammation-induced hypoxia, which is relevant to any inflamed tissue. Moreover, it is believed that some SLO $\mathrm{T}_{\mathrm{RM}}$ are derived from emigrants of $\mathrm{T}_{\mathrm{RM}}$ originally differentiated in nonlymphoid tissues (85). Microanatomical availability and receipt of additional signals, such as from TGF- $\beta$, would also influence residency programming. It is possible that hypoxia is not a universal driver of $\mathrm{T}_{\mathrm{RM}}$ in all tissues, just as $T_{R M}$ in different organs vary in their requirement for IL-15 (60). Sources of active TGF- $\beta$ for $T_{R M}$ 
differentiation may also differ between tissues: provided by keratinocytes in the skin, Kupffer cells in the liver, dendritic cells in lymphoid and other organs, and perhaps monocytes and/or macrophages. These cells express integrins necessary to release active TGF- $\beta$ from the latent form present in the environment - either bound to extracellular matrix via latent TGF- $\beta$ binding protein or anchored to immune cell membranes via glycoprotein-A repetitions predominant protein (GARP/LRRC32) or LRRC33 (27, 86-91).

Our findings also raise questions regarding the role of metabolism in $\mathrm{T}_{\mathrm{RM}}$ differentiation. Hombrink et al. suggested that a major role of Notch signaling in lung $\mathrm{T}_{\mathrm{RM}}$ is regulation of metabolic programs because inhibition of Notch signaling affected genes involved in glycolysis, oxidative phosphorylation, and fatty acid metabolism pathways (23). It has also been suggested that deletion of the purinergic receptor P2RX7, which is known to modulate glycolysis, impairs $\mathrm{T}_{\mathrm{RM}}$ formation via metabolic dysregulation, as P2RX7-deficient cells displayed decreased mitochondrial mass and function, defective aerobic glycolysis, and impaired glucose uptake (92-94). While hypoxia reportedly promotes effector differentiation in T cells via HIF-driven glycolysis, TGF- $\beta$ seems to be important for memory $\mathrm{T}$ cell formation, likely via effects on mitochondria (95-97). In contrast to hypoxia, few reports describe the role of TGF- $\beta$ in T cell metabolism. It has been shown that TGF- $\beta$ can increase mitochondrial membrane potential (a measure of mitochondrial activity) in $\mathrm{T}$ cells and that $\mathrm{CD} 8^{+} \mathrm{CD} 103^{+}$ tumor-specific $\mathrm{T}$ cells have increased spare respiratory capacity; however, the connection to oxidative phosphorylation and/or fatty acid metabolism is unclear and may also be dependent on $\mathrm{T}$ cell differentiation status (97-100). Interestingly, P2RX7 activity induces HIF-1 $\alpha$ (likely involved in P2RX7's regulation of T cell metabolism) as well as TGF- $\beta$ receptor II, thereby increasing sensitivity to TGF- $\beta$ and providing another possible avenue of integration of these pathways in endogenous $\mathrm{T}_{\mathrm{RM}}(93,97,101)$.

How hypoxia and TGF- $\beta$ synergize to induce $\mathrm{CD} 69^{+} \mathrm{CD} 103^{+}$cells remains an open question, and our results indicate that HIF-mediated mechanisms are involved. HIFs are known to modulate several $\mathrm{T}_{\mathrm{RM}}$ phenotype features, including upregulation of CD69 and TNFRSF9, and downregulation of SELL and S1PR1, as reflected in our results $(29,95,102,103)$. Further, inhibition of HIF- $1 \alpha / \beta$ complex formation by HIF- $1 \beta$ deletion in murine $\mathrm{T}$ cells maintained CD62L expression, causing their accumulation in lymph nodes and preventing migration to nonlymphoid tissues. (102). Our work and that of others suggests TGF- $\beta$ may potentiate HIF activity by upregulating HIF1A and promoting HIF stabilization and activity via downregulation of the negative regulators PHD2 and CITED2 $(104,105)$. Notably, HIF-1 $\alpha$ can also be induced by other stimuli reportedly involved in $\mathrm{T}_{\mathrm{RM}}$ generation and/or maintenance, namely IL-15, TNF- $\alpha$, and P2RX7 stimulation by extracellular ATP $(101,106,107)$. Moreover, IL-15 and TNF- $\alpha$ can induce CD69 expression similarly to hypoxia $(8,108)$. Thus, it is unclear to what extent hypoxia is a relevant cue in vivo or whether hypoxia in our system mimics the effects induced by other inflammatory stimuli. However, the cooperation we observed between hypoxia and IL-15 suggests these cues are complementary rather than redundant. We also observed changes in expression of several epigenetic regulators, suggesting hypoxia-induced chromatin remodeling may alter accessibility to hypoxia-inducible transcription factors such as HIFs and the glucocorticoid receptor as well as TGF- $\beta$-inducible transcription factors such as SMAD3 and EGR2 (109). Future studies are warranted to further dissect the mechanism via which hypoxia and TGF- $\beta$ synergize to induce the $\mathrm{T}_{\mathrm{RM}}$ phenotype.

In recent years multiple reports have suggested that $\mathrm{TIL}_{\mathrm{RM}}$ are important in antitumor immunity. Specifically, the accumulation of CD103 ${ }^{+}$TILs in a wide array of solid tumor malignancies, including breast, lung, ovarian, pancreatic, and melanoma, is associated with favorable prognosis (41-45). In addition, murine model studies have shown that skin $\mathrm{T}_{\mathrm{RM}}$ are protective against melanoma $(110,111)$. Thus, there is much interest in leveraging resident phenotype $\mathrm{T}$ cells for immunotherapy; however, current approaches focus on using vaccination to induce these cells in vivo because endogenous $\mathrm{T}_{\mathrm{RM}}$ are difficult to isolate and culture, and there is no reliable method to generate these cells in vitro $(92,112,113)$. The method described in this study may enable in vitro generation of $\mathrm{T}_{\mathrm{RM}}$ phenotype cells and has the potential for application to multiple existing adoptive cellular therapy (ACT) modalities. The elevated PD-1 expression on $\mathrm{i}-\mathrm{T}_{\mathrm{RM}}$ make them attractive for combination with PD-1 blockade. Indeed, a recent study in metastatic melanoma patients reported that $\mathrm{CD}_{103^{+}}$TILs significantly expanded during anti-PD-1 therapy (114). There is also potential for $\mathrm{i}-\mathrm{T}_{\mathrm{RM}}$ ACT to treat viral diseases: the importance of $\mathrm{T}_{\mathrm{RM}}$ in antiviral immunity is well established, and a recent study found that elite HIV controllers have high magnitudes of HIV-specific $\mathrm{T}_{\mathrm{RM}}$ in their lymphoid tissues, suggesting that these cells may control chronic viral infections (26). We show that even in unfavorable conditions $\left(20 \% \mathrm{O}_{2}\right.$ with IL-2) $\mathrm{i}-\mathrm{T}_{\mathrm{RM}}$ can maintain their phenotype because by 48 hours approximately $30 \%$ of the cells remained $\mathrm{CD} 9^{+} \mathrm{CD} 103^{+}$. In addition, since preparation of ACT products for administration typically occurs within a 12-hour period, we believe the majority of $\mathrm{i}-\mathrm{T}_{\mathrm{RM}}$ would retain their phenotype during processing, as well as 
in vivo upon receiving suitable environmental cues. We are applying the findings of this study to expansion protocols for production of $\mathrm{i}-\mathrm{T}_{\mathrm{RM}}$ in sufficient quantity for therapeutic purposes.

To our knowledge this study is the first to recapitulate $\mathrm{T}_{\mathrm{RM}}$ phenotype and transcriptional signature in vitro from human peripheral blood-derived $\mathrm{T}$ cells, as well as the first to identify hypoxia as a cue for the human $\mathrm{T}_{\mathrm{RM}}$ differentiation program. While there are obvious limitations to experiments that can be conducted in humans, we believe the studies described provide compelling evidence that hypoxia is an environmental cue that can contribute to acquisition of a $\mathrm{T}_{\mathrm{RM}}$ phenotype, supported by the observation that hypoxia + TGF- $\beta$ i- $\mathrm{T}_{\mathrm{RM}}$ recapitulate the transcriptional and proteomic landscape of endogenous $\mathrm{T}_{\mathrm{RM}}$. These observations suggest that lower oxygen tensions such as those found in peripheral tissues, sites of inflammation, and tumors can promote the $\mathrm{T}_{\mathrm{RM}}$ differentiation program. In vivo studies will be necessary to determine whether hypoxia and/or HIFs can contribute to $\mathrm{T}_{\mathrm{RM}}$ differentiation in peripheral tissues and/or tumors and to determine whether $\mathrm{i}-\mathrm{T}_{\mathrm{RM}}$ can establish tissue residency after adoptive transfer.

\section{Methods}

\section{Cell isolation and in vitro cell culture}

Healthy donor PBMCs were collected via leukapheresis and stored in liquid nitrogen until use. CD8 ${ }^{+} \mathrm{T}$ cells were enriched from PBMCs using STEMCELL Technologies EasySep kits. Cells were then stained with fluorochrome-conjugated antibodies against CD8 (SK1), CD45RA (HI100), and CCR7 (G043H7) (all BioLegend, clones in parentheses). Naive $\mathrm{CD} 8^{+} \mathrm{CD} 45 \mathrm{RA}^{+} \mathrm{CCR} 7^{+} \mathrm{T}$ cells were sorted using a FACSAria IIIu or Fusion cell sorter (BD Biosciences). Sorted naive $\mathrm{CD} 8^{+} \mathrm{T}$ cells were resuspended in T cell culture media (RPMI, 10\% FBS, L-glutamine, penicillin-streptomycin) with $10 \mathrm{IU} / \mathrm{mL}$ rhIL-2 (Prometheus) and equilibrated overnight to $2 \% \mathrm{O}_{2}$ in a hypoxic chamber (Coy Laboratory Products) or in a standard cell culture incubator $\left(\sim 20 \% \mathrm{O}_{2}\right.$, Thermo Fisher Scientific). Cells were then activated with anti-CD3/anti-CD28 beads (Gibco, Thermo Fisher Scientific) at 3 cells per bead for 4 days. On day $4,1.25 \mathrm{ng} / \mathrm{mL}$ rhTGF- $\beta 1$ (BioLegend) was added, and cells were cultured for an additional 2 days. For phenotype stability assays $\mathrm{i}-\mathrm{T}_{\mathrm{RM}}$ were generated as described, sorted, and resuspended in media pre-equilibrated to $20 \% \mathrm{O}_{2}$ or $2 \% \mathrm{O}_{2}$ with $20 \mathrm{IU} / \mathrm{mL}$ rhIL-2 (Prometheus) or $10 \mathrm{ng} /$ $\mathrm{mL}$ rhIL-15 (R\&D Systems, Bio-Techne), with or without $1.25 \mathrm{ng} / \mathrm{mL}$ rhTGF- $\beta 1$ (BioLegend).

\section{Flow cytometry}

For analysis of human $\mathrm{T}_{\mathrm{RM}^{-}}$-associated markers, beads were removed, and cells were washed once in staining buffer and stained with Live/Dead Fixable Aqua (Life Technologies, Thermo Fisher Scientific) and fluorochrome-conjugated antibodies against CD8 (SK1), CD69 (FN50), CD103 (ber-ACT8), PD-1 (EH12.2H7), CD101 (BB27), CXCR6 (K041E5), and CD49a (TS2/7) (all BioLegend, clones in parentheses). After stain ing, cells were fixed with Fixation Buffer (BioLegend) and stored in staining buffer until analysis. Stained cells were analyzed using an ACEA Novocyte 3000 flow cytometer. Single fluorochrome-stained compensation beads (UltraComp, eBioscience, Thermo Fisher Scientific) and FMO samples were used as controls. Data were analyzed using FlowJo software (BD Biosciences).

\section{qRT-PCR or qPCR}

For analysis of human $\mathrm{T}_{\mathrm{RM}}$-associated gene expression, cells were separated from beads and washed once in PBS. RNA was isolated using the QIAGEN RNeasy Plus Mini Kit. When necessary RNA was further purified/concentrated using the QIAGEN RNeasy MinElute Cleanup Kit. First-strand cDNA was synthesized using M-MLV Reverse Transcriptase (Thermo Fisher Scientific). qRT-PCR was performed using the QuantStudio 5 Real-Time PCR System and PowerUp SYBR Green Master Mix (Applied Biosystems, Thermo Fisher Scientific). Relative mRNA gene expression was normalized to the housekeeping gene RPL13A. Primers used are listed in Supplemental Table 3.

\section{RNA-Seq transcriptome analysis}

Cells were sorted using a FACSAria IIIu cell sorter before RNA isolation using the RNeasy Plus Mini Kit followed by the RNeasy MinElute Cleanup Kit.

Regarding batch1. The library was constructed using the Illumina TruSeq Stranded mRNA kit. RNA-Seq was conducted by the Sequencing and Non-Coding RNA Program of UT MD Anderson Cancer Center using the Illumina NextSeq500 platform. Raw reads were mapped to the Homo sapiens reference genome 
and transcriptome (GRCh38, GENCODEV23) by HISAT2 (version 2.1.0; ref. 115). Htseq-count (version 2.1.0) was used to get the counts for genes. $R$ and Bioconductor packages DESeq2 (version 1.14.1) were used to identify DEGs (116). Genes (mRNA only, taking the protein-coding genes for $P$ value adjustment) with FDR $<0.05$ and | fold change $\mid \geq 2$ were considered differentially expressed. $\mathrm{R}$ and Bioconductor package fgsea (version 1.10.0) was used to conduct GSEA. Gene sets were derived from several previously published data sets. The Nath et al. TGF- $\beta$ signatures, Savas et al. TIL signatures, and Gupta et al. and Quigley et al. exhaustion signatures were derived from published differential expression tables $(41,51,52,117)$. The human $\mathrm{T}_{\mathrm{RM}}$ signature was constructed from several studies $(22,23,26,36)$. For the lung and skin $\mathrm{T}_{\mathrm{RM}}$ signatures, gene expression data were obtained from the Gene Expression Omnibus database (accessions GSE61397 and GSE83637) and analyzed using GEO2R or DESeq2, respectively $(23,36)$. FDR-adjusted $P$ values less than 0.05 were considered significant. For analysis of intersection/overlap between gene sets, fold change thresholds were adjusted to \pm 1.5 and FDR $\leq 0.5$ to account for the reduced sensitivity of microarray technology.

Regarding batch2. The library was constructed using the NEBNext Ultra RNA Library Prep Kit for Illumina (New England Biolabs). mRNA sequencing was conducted by Novogene Corporation Inc. using the Illumina NovaSeq platform. Raw reads were mapped to the Homo sapiens reference genome and transcriptome (GRCh38, GENCODEV23) by HISAT2 (version: 2.1.0). Htseq-count (version: 2.1.0) was used to get the counts for genes. For analysis relevant to Figures 6 and 7: DEGs were determined using the likelihood ratio test function offered by Bioconductor R package DESeq2 (version 1.28.1). The genes (mRNA only, taking the protein-coding genes for $P$ value adjustment) with $P$ adj $<0.001$ were selected as candidates. In order to decrease any sample-specific variation between the 2 batches of RNA-Seq data sets, supervised surrogate variable analysis using Bioconductor R package sva (version 3.36.0) based on the expression of human housekeeping genes (3804 genes) was performed $(118,119)$. For analysis relevant to Figure 8: R and Bioconductor package DESeq2 (version 1.28.1) was used to identify DEGs. Genes (mRNA only, taking the protein-coding genes for $P$ value adjustment) with FDR $\leq 0.05$ and $\mid$ fold change $\mid \geq 2$ were considered differentially expressed.

Regarding both batches. Downstream logical and statistical outputs were generated using customized R scripts with packages dplyr (version 1.0.2), tidyr (version 1.1.2), tibble (version 3.0.4), stringi (version 1.5.3), tidyverse (version 1.3.0), clusterProfiler (version 3.16.1), and ggplot2 (version 3.3.2). Data have been deposited in the European Genome-phenome Archive (EGA) under the EGA ID/accession number EGAS00001005286.

Pathway analysis. Functional analysis of significant DEGs (FDR $<0.05$ and $\mid$ fold change $\mid>2)$ was done with IPA software (version 60467501, QIAGEN) using all genes in the Ingenuity Knowledge Base as the reference set and right-tailed Fisher's exact test in a core analysis to determine if pathways were significantly altered between conditions $\left(-\log _{10}[P\right.$ value $\left.]>1.3\right)$.

GO. Differentially expressed gene lists were tested for enrichment of GO pathways using the PANTHER classification system web-based gene list analysis tool, version 16.0 (120). The statistical overrepresentation test (released 20200728) was performed using the GO biological processes complete annotation data set and Fisher's exact test with FDR $<0.05$ correction for multiple testing.

\section{Statistics}

Graphical presentation and statistical analysis of the data were performed using GraphPad Prism (Version 8). Data are displayed as mean \pm SEM. Samples were matched/paired unless otherwise indicated. Results between experimental groups were compared using statistical tests described in the figure legends $(t$ tests always 2-tailed and 1- or 2-way ANOVA always followed by Tukey's multiple comparisons test, unless otherwise indicated). $P<0.05$ was considered statistically significant.

\section{Study approval}

All human sample collection was performed with informed consent and approved by the institutional review board of UT MD Anderson Cancer Center.

\section{Author contributions}

FH conceptualized the study, designed and performed experiments, collected and analyzed data, and wrote the paper. YC analyzed RNA-Seq data. RMS performed experiments. JW analyzed data, provided intellectual contributions, and edited the paper. CY oversaw the study, provided intellectual contributions, and edited the paper. 


\section{Acknowledgments}

We thank the South Campus Flow Cytometry \& Cell Sorting Core Laboratory of UT MD Anderson Cancer Center, which is supported by National Cancer Institute/NIH P30CA016672. We thank Stephen C. Jameson and Kimberly S. Schluns for their feedback on the manuscript and Sirisha Yadugiri for her assistance in figure preparation. This research was supported by the Parker Institute for Cancer Immunotherapy. CY is a member of the Parker Institute for Cancer Immunotherapy.

Address correspondence to: Cassian Yee, 7455 Fannin Street, Unit Number: 904, Houston, Texas 77054, USA. Phone: 713.563.3750; Email: cyee@mdanderson.org.

1. Masopust D, et al. Dynamic T cell migration program provides resident memory within intestinal epithelium. $J$ Exp Med. 2010;207(3):553-564.

2. Mackay LK, et al. The developmental pathway for CD103(+)CD8+ tissue-resident memory T cells of skin. Nat Immunol. 2013;14(12):1294-1301.

3. Mackay LK, et al. T-box transcription factors combine with the cytokines TGF- $\beta$ and IL-15 to control tissue-resident memory T cell fate. Immunity. 2015;43(6):1101-1111.

4. Casey KA, et al. Antigen-independent differentiation and maintenance of effector-like resident memory T cells in tissues. $J$ Immunol. 2012;188(10):4866-4875.

5. Zhang N, Bevan MJ. Transforming growth factor- $\beta$ signaling controls the formation and maintenance of gut-resident memory T cells by regulating migration and retention. Immunity. 2013;39(4):687-696.

6. Bergsbaken T, et al. Local inflammatory cues regulate differentiation and persistence of CD8 ${ }^{+}$tissue-resident memory $\mathrm{T}$ cells. Cell Rep. 2017;19(1):114-124.

7. Sheridan BS, et al. Oral infection drives a distinct population of intestinal resident memory CD8(+) T cells with enhanced protective function. Immunity. 2014;40(5):747-757.

8. Pallett LJ, et al. IL-2(high) tissue-resident T cells in the human liver: sentinels for hepatotropic infection. J Exp Med. 2017;214(6):1567-1580.

9. Wakim LM, et al. Antibody-targeted vaccination to lung dendritic cells generates tissue-resident memory CD8 T cells that are highly protective against influenza virus infection. Mucosal Immunol. 2015;8(5):1060-1071.

10. Skon CN, et al. Transcriptional downregulation of S1pr1 is requiredfor the establishment of resident memory CD8+ T cells. Nat Immunol. 2013;14(12):1285-1293.

11. Atkuri KR, et al. Culturing at atmospheric oxygen levels impacts lymphocyte function. Proc Natl Acad Sci US A. 2005;102(10):3756-3759.

12. Caldwell CC, et al. Differential effects of physiologically relevant hypoxic conditions on T lymphocyte development and effector functions. J Immunol. 2001;167(11):6140-6149.

13. Huang JH, et al. Requirements for T lymphocyte migration in explanted lymph nodes. J Immunol. 2007;178(12):7747-7755.

14. Gillies RM, et al. Immunohistochemical assessment of intrinsic and extrinsic markers of hypoxia in reproductive tissue: differential expression of HIF1 $\alpha$ and HIF2 $\alpha$ in rat oviduct and endometrium. J Mol Histol. 2011;42(4):341-354.

15. Karhausen J, et al. Epithelial hypoxia-inducible factor-1 is protective in murine experimental colitis. J Clin Invest. 2004;114(8):1098-1106.

16. Rezvani HR, et al. HIF-1 $\alpha$ in epidermis: oxygen sensing, cutaneous angiogenesis, cancer, and non-cancer disorders. J Invest Dermatol. 2011;131(9):1793-1805.

17. Boyman $\mathrm{O}$, et al. Spontaneous development of psoriasis in a new animal model shows an essential role for resident $\mathrm{T}$ cells and tumor necrosis factor-alpha. J Exp Med. 2004;199(5):731-736.

18. Gebhardt T, et al. Memory T cells in nonlymphoid tissue that provide enhanced local immunity during infection with herpes simplex virus. Nat Immunol. 2009;10(5):524-530.

19. Colgan SP, Taylor CT. Hypoxia: an alarm signal during intestinal inflammation. Nat Rev Gastroenterol Hepatol. 2010;7(5):281-287.

20. Nizet V, Johnson RS. Interdependence of hypoxic and innate immune responses. Nat Rev Immunol. 2009;9(9):609-617.

21. Campbell EL, et al. Transmigrating neutrophils shape the mucosal microenvironment through localized oxygen depletion to influence resolution of inflammation. Immunity. 2014;40(1):66-77.

22. Kumar BV, et al. Human tissue-resident memory T cells are defined by core transcriptional and functional signatures in lymphoid and mucosal sites. Cell Rep. 2017;20(12):2921-2934.

23. Hombrink P, et al. Programs for the persistence, vigilance and control of human CD8(+) lung-resident memory T cells. Nat Immunol. 2016;17(12):1467-1478.

24. Mackay LK, et al. Hobit and Blimp1 instruct a universal transcriptional program of tissue residency in lymphocytes. Science. 2016;352(6284):459-463.

25. Atkuri KR, et al. Importance of culturing primary lymphocytes at physiological oxygen levels. Proc Natl Acad Sci U S A. 2007;104(11):4547-4552.

26. Buggert $\mathrm{M}$, et al. Identification and characterization of HIV-specific resident memory $\mathrm{CD} 8^{+} \mathrm{T}$ cells in human lymphoid tissue. Sci Immunol. 2018;3(24):eaar4526.

27. Mani V, et al. Migratory DCs activate TGF- $\beta$ to precondition naïve CD8 ${ }^{+} \mathrm{T}$ cells for tissue-resident memory fate. Science. 2019;366(6462):eaav5728.

28. Thome JJ, et al. Spatial map of human T cell compartmentalization and maintenance over decades of life. Cell. 2014;159(4):814-828.

29. Labiano S, et al. CD69 is a direct HIF-1 $\alpha$ target gene in hypoxia as a mechanism enhancing expression on tumor-infiltrating T 
lymphocytes. Oncoimmunology. 2017;6(4):e1283468.

30. Hadley GA, et al. Regulation of the epithelial cell-specific integrin, CD103, by human CD8+ cytolytic T lymphocytes. Transplantation 1999;67(11):1418-1425.

31. Mokrani M, et al. Smad and NFAT pathways cooperate to induce CD103 expression in human CD8 T lymphocytes. J Immunol. 2014;192(5):2471-2479.

32. Weisberg SP, et al. Tissue-resident memory T cells mediate immune homeostasis in the human pancreas through the PD-1/ PD-L1 pathway. Cell Rep. 2019;29(12):3916-3932.e5.

33. Snyder ME, et al. Generation and persistence of human tissue-resident memory T cells in lung transplantation. Sci Immunol. 2019;4(33):eaav5581.

34. Kopan R, Ilagan MX. The canonical Notch signaling pathway: unfolding the activation mechanism. Cell. 2009;137(2):216-233.

35. Schenkel JM, et al. Sensing and alarm function of resident memory CD8 ${ }^{+}$T cells. Nat Immunol. 2013;14(5):509-513.

36. Cheuk S, et al. CD49a expression defines tissue-resident $\mathrm{CD}^{+} \mathrm{T}$ cells poised for cytotoxic function in human skin. Immunity. 2017;46(2):287-300.

37. Du N, et al. EGR2 is critical for peripheral naïve T-cell differentiation and the T-cell response to influenza. Proc Natl Acad Sci U S A. 2014;111(46):16484-16489.

38. Yu B, et al. Epigenetic landscapes reveal transcription factors that regulate CD8(+) T cell differentiation. Nat Immunol. 2017;18(5):573-582.

39. Leonard MO, et al. Potentiation of glucocorticoid activity in hypoxia through induction of the glucocorticoid receptor. J Immunol. 2005; 174(4):2250-2257.

40. Strobl J, et al. Long-term skin-resident memory T cells proliferate in situ and are involved in human graft-versus-host disease Sci Transl Med. 2020;12(570):eabb7028.

41. Savas P, et al. Single-cell profiling of breast cancer T cells reveals a tissue-resident memory subset associated with improved prognosis. Nat Med. 2018;24(7):986-993.

42. Kim Y, et al. Prognostic significance of CD103+ immune cells in solid tumor: a systemic review and meta-analysis. Sci Rep. 2019;9(1):3808.

43. Smazynski J, Webb JR. Resident memory-like tumor-infiltrating lymphocytes $\left(\mathrm{TIL}_{\mathrm{RM}}\right)$ : latest players in the immuno-oncology repertoire. Front Immunol. 2018;9:1741

44. Duhen T, et al. Co-expression of CD39 and CD103 identifies tumor-reactive CD8 T cells in human solid tumors. Nat Commun 2018;9(1):2724.

45. Ganesan AP, et al. Tissue-resident memory features are linked to the magnitude of cytotoxic $\mathrm{T}$ cell responses in human lung cancer. Nat Immunol. 2017;18(8):940-950.

46. Arina A, et al. Tumor-reprogrammed resident T cells resist radiation to control tumors. Nat Commun. 2019;10(1):3959

47. Rockwell S, et al. Hypoxia and radiation therapy: past history, ongoing research, and future promise. Curr Mol Med. 2009;9(4):442-458.

48. Bouquet $\mathrm{F}$, et al. TGF $\beta 1$ inhibition increases the radiosensitivity of breast cancer cells in vitro and promotes tumor control by radiation in vivo. Clin Cancer Res. 2011;17(21):6754-6765

49. Tinoco R, et al. Cell-intrinsic transforming growth factor-beta signaling mediates virus-specific CD8+ T cell deletion and viral persistence in vivo. Immunity. 2009;31(1):145-157.

50. Scharping NE, et al. Mitochondrial stress induced by continuous stimulation under hypoxia rapidly drives $\mathrm{T}$ cell exhaustion. Nat Immunol. 2021;22(2):205-215.

51. Quigley M, et al. Transcriptional analysis of HIV-specific CD8+ T cells shows that PD-1 inhibits T cell function by upregulating BATF. Nat Med. 2010;16(10):1147-1151.

52. Gupta PK, et al. CD39 expression identifies terminally exhausted CD8+ T Cells. PLoS Pathog. 2015;11(10):e1005177.

53. Aberle H. Axon guidance and collective cell migration by substrate-derived attractants. Front Mol Neurosci. $2019 ; 12: 148$.

54. Takamatsu H, et al. Regulation of immune cell responses by semaphorins and their receptors. Cell Mol Immunol. 2010;7(2):83-88.

55. Poznansky MC, et al. Active movement of T cells away from a chemokine. Nat Med. 2000;6(5):543-548.

56. Pocock R, Hobert O. Oxygen levels affect axon guidance and neuronal migration in Caenorhabditis elegans. Nat Neurosci. 2008;11(8):894-900.

57. Hachim IY, et al. Transforming growth factor-beta regulation of ephrin type-A receptor 4 signaling in breast cancer cellular migration. Sci Rep. 2017;7(1):14976.

58. Yi JJ, et al. TGF-beta signaling specifies axons during brain development. Cell. 2010;142(1):144-157.

59. Tamagnone L. Emerging role of semaphorins as major regulatory signals and potential therapeutic targets in cancer. Cancer Cell. 2012;22(2):145-152.

60. Schenkel JM, et al. IL-15-independent maintenance of tissue-resident and boosted effector memory CD8 T cells. J Immunol. 2016;196(9):3920-3926.

61. Holz LE, et al. CD8 ${ }^{+} \mathrm{T}$ cell activation leads to constitutive formation of liver tissue-resident memory $\mathrm{T}$ cells that seed a large and flexible niche in the liver. Cell Rep. 2018;25(1):68-79.

62. Adachi T, et al. Hair follicle-derived IL-7 and IL-15 mediate skin-resident memory T cell homeostasis and lymphoma. Nat Med. 2015;21(11):1272-1279.

63. Frizzell H, et al. Organ-specific isoform selection of fatty acid-binding proteins in tissue-resident lymphocytes. Sci Immunol. 2020;5(46):eaay9283.

64. Fonseca R, et al. Developmental plasticity allows outside-in immune responses by resident memory T cells. Nat Immunol. 2020;21(4):412-421.

65. Bromley SK, et al. CD49a regulates cutaneous resident memory CD8 ${ }^{+}$T cell persistence and response. Cell Rep. 2020;32(9):108085

66. Epstein AC, et al. C. elegans EGL-9 and mammalian homologs define a family of dioxygenases that regulate HIF by prolyl hydroxylation. Cell. 2001;107(1):43-54

67. Yoon $\mathrm{H}$, et al. CITED2 controls the hypoxic signaling by snatching p300 from the two distinct activation domains of HIF-1 $\alpha$. Biochim Biophys Acta. 2011;1813(12):2008-2016. 
68. Bellot G, et al. Hypoxia-induced autophagy is mediated through hypoxia-inducible factor induction of BNIP3 and BNIP3L via their BH3 domains. Mol Cell Biol. 2009;29(10):2570-2581.

69. Puleston DJ, et al. Autophagy is a critical regulator of memory CD8(+) T cell formation. Elife. 2014;3.

70. Swadling L, et al. Human liver memory CD8+ T cells use autophagy for tissue residence. Cell Rep. 2020;30(3):687-698.e6.

71. Jaakkola P, et al. Targeting of HIF-alpha to the von Hippel-Lindau ubiquitylation complex by O2-regulated prolyl hydroxylation. Science. 2001;292(5516):468-472.

72. Besarab A, et al. Randomized placebo-controlled dose-ranging and pharmacodynamics study of roxadustat (FG-4592) to treat anemia in nondialysis-dependent chronic kidney disease (NDD-CKD) patients. Nephrol Dial Transplant. 2015;30(10):1665-1673.

73. Yeh TL, et al. Molecular and cellular mechanisms of HIF prolyl hydroxylase inhibitors in clinical trials. Chem Sci. 2017;8(11):7651-7668

74. Islam MS, et al. 2-oxoglutarate-dependent oxygenases. Annu Rev Biochem. 2018;87(1):585-620.

75. Kurd NS, et al. Early precursors and molecular determinants of tissue-resident memory CD8 ${ }^{+} \mathrm{T}$ lymphocytes revealed by single-cell RNA sequencing. Sci Immunol. 2020;5(47):eaaz6894.

76. Hayward SL, et al. Environmental cues regulate epigenetic reprogramming of airway-resident memory CD8 ${ }^{+} \mathrm{T}$ cells. Nat Immunol. 2020;21(3):309-320.

77. FitzPatrick MEB, et al. Human intestinal tissue-resident memory T cells comprise transcriptionally and functionally distinct subsets. Cell Rep. 2021;34(3):108661.

78. Wong MT, et al. A high-dimensional atlas of human T cell diversity reveals tissue-specific trafficking and cytokine signatures. Immunity. 2016;45(2):442-456.

79. De la Garza MM, et al. COPD-Type lung inflammation promotes K-ras mutant lung cancer through epithelial HIF-1 $\alpha$ mediated tumor angiogenesis and proliferation. Oncotarget. 2018;9(68):32972-32983.

80. Le QT, et al. An evaluation of tumor oxygenation and gene expression in patients with early stage non-small cell lung cancers Clin Cancer Res. 2006;12(5):1507-1514.

81. Polosukhin VV, et al. Association of progressive structural changes in the bronchial epithelium with subepithelial fibrous remodeling a potential role for hypoxia. Virchows Arch. 2007;451(4):793-803

82. Carreau A, et al. Why is the partial oxygen pressure of human tissues a crucial parameter? Small molecules and hypoxia. $J$ Cell Mol Med. 2011;15(6):1239-1253.

83. Koh MY, Powis G. Passing the baton: the HIF switch. Trends Biochem Sci. 2012;37(9):364-372.

84. Evans SM, et al. Oxygen levels in normal and previously irradiated human skin as assessed by EF5 binding. J Invest Dermatol. 2006;126(12):2596-2606.

85. Beura LK, et al. T cells in nonlymphoid tissues give rise to lymph-node-resident memory T cells. Immunity. 2018;48(2):327-338

86. Hirai T, et al. Keratinocyte-mediated activation of the cytokine TGF- $\beta$ maintains skin recirculating memory CD ${ }^{+} \mathrm{T}$ Cells. Immunity. 2019;50(5):1249-1261.

87. Kelly A, et al. Human monocytes and macrophages regulate immune tolerance via integrin $\alpha v \beta 8$-mediated TGF $\beta$ activation $J$ Exp Med. 2018;215(11):2725-2736.

88. Mohammed J, et al. Stromal cells control the epithelial residence of DCs and memory T cells by regulated activation of TGF- $\beta$. Nat Immunol. 2016;17(4):414-421.

89. Bourdely $\mathrm{P}$, et al. Transcriptional and functional analysis of $\mathrm{CD} 1 \mathrm{c}(+)$ human dendritic cells identifies a CD163(+) subset priming CD8(+)CD103(+) T cells. Immunity. 2020;53(2):335-352.

90. Qin Y, et al. A milieu molecule for TGF- $\beta$ required for microglia function in the nervous system. Cell. 2018;174(1):156-171.

91. Watanabe R, et al. Human skin is protected by four functionally and phenotypically discrete populations of resident and recirculating memory T cells. Sci Transl Med. 2015;7(279):279ra39.

92. Borges da Silva $\mathrm{H}$, et al. ARTC2.2/P2RX7 signaling during cell isolation distorts function and quantification of tissue-resident CD8(+) T cell and invariant NKT Subsets. J Immunol. 2019;202(7):2153-2163.

93. Amoroso F, et al. The P2X7 receptor is a key modulator of aerobic glycolysis. Cell Death Dis. 2012;3:e370.

94. Borges da Silva $\mathrm{H}$, et al. The purinergic receptor P2RX7 directs metabolic fitness of long-lived memory CD8. Nature. 2018;559(7713):264-268.

95. Doedens AL, et al. Hypoxia-inducible factors enhance the effector responses of CD8(+) T cells to persistent antigen. Nat Immunol. 2013;14(11):1173-1182.

96. Phan AT, et al. Constitutive glycolytic metabolism supports $\mathrm{CD} 8^{+} \mathrm{T}$ cell effector memory differentiation during viral infection. Immunity. 2016;45(5):1024-1037.

97. Borges da Silva H, et al. Sensing of ATP via the purinergic receptor P2RX7 promotes CD8(+) Trm cell generation by enhancing their sensitivity to the cytokine TGF-beta. Immunity. 2020;53(1):158-171.

98. Dimeloe S, et al. Tumor-derived TGF- $\beta$ inhibits mitochondrial respiration to suppress IFN- $\gamma$ production by human $\mathrm{CD}^{+} \mathrm{T}$ cells. Sci Signal. 2019;12(599):eaav3334.

99. Priyadharshini B, et al. Cutting edge: TGF- $\beta$ and phosphatidylinositol 3-kinase signals modulate distinct metabolism of regulatory T cell subsets. J Immunol. 2018;201(8):2215-2219.

100. Abd Hamid M, , et al. Self-maintaining CD $103^{+}$cancer-specific T cells are highly energetic with rapid cytotoxic and effector responses. Cancer Immunol Res. 2020;8(2):203-216.

101. Mascanfroni ID, et al. Metabolic control of type 1 regulatory T cell differentiation by AHR and HIF1- $\alpha$. Nat Med. 2015;21(6):638-646.

102. Finlay DK, et al. PDK1 regulation of $\mathrm{mTOR}$ and hypoxia-inducible factor 1 integrate metabolism and migration of CD8+ T cells. J Exp Med. 2012;209(13):2441-2453.

103. Palazon A, et al. The HIF-1 $\alpha$ hypoxia response in tumor-infiltrating T lymphocytes induces functional CD137 (4-1BB) for immunotherapy. Cancer Discov. 2012;2(7):608-623.

104.McMahon S, et al. Transforming growth factor beta1 induces hypoxia-inducible factor-1 stabilization through selective inhibition of PHD2 expression. J Biol Chem. 2006;281(34):24171-24181.

105. Chou YT, Yang YC. Post-transcriptional control of Cited2 by transforming growth factor beta. Regulation via Smads and 
Cited2 coding region. J Biol Chem. 2006;281(27):18451-18462.

106. Coulibaly A, et al. Interleukin-15 signaling in HIF-1 $\alpha$ regulation in natural killer cells, insights through mathematical models. Front Immunol. 2019;10:2401.

107.Jung Y, et al. Hypoxia-inducible factor induction by tumour necrosis factor in normoxic cells requires receptor-interacting proteindependent nuclear factor kappa B activation. Biochem J. 2003;370(pt 3):1011-1017.

108.Lopez-Cabrera M, et al. Transcriptional regulation of the gene encoding the human C-type lectin leukocyte receptor AIM/CD69 and functional characterization of its tumor necrosis factor-alpha-responsive elements. J Biol Chem. 1995;270(37):21545-21551.

109.Fang F, et al. The early growth response gene Egr2 (Alias Krox20) is a novel transcriptional target of transforming growth factor- $\beta$ that is up-regulated in systemic sclerosis and mediates profibrotic responses. Am J Pathol. 2011;178(5):2077-2090.

110.Malik BT, et al. Resident memory T cells in the skin mediate durable immunity to melanoma. Sci Immunol. 2017;2(10):eaam6346.

111. Park SL, et al. Tissue-resident memory CD $8(+) \mathrm{T}$ cells promote melanoma-immune equilibrium in skin. Nature 2019;565(7739):366-371.

112. Nizard M, et al. Induction of resident memory T cells enhances the efficacy of cancer vaccine. Nat Commun. 2017;8:15221.

113. Sandoval F, et al. Mucosal imprinting of vaccine-induced $\mathrm{CD}^{+} \mathrm{T}$ cells is crucial to inhibit the growth of mucosal tumors. Sci Transl Med. 2013;5(172):172ra20.

114.Edwards J, et al. CD103 ${ }^{+}$Tumor-resident $\mathrm{CD} 8^{+} \mathrm{T}$ cells are associated with improved survival in immunotherapy-naïve melanoma patients and expand significantly during anti-PD-1 treatment. Clin Cancer Res. 2018;24(13):3036-3045.

115. Kim D, et al. HISAT: a fast spliced aligner with low memory requirements. Nat Methods. 2015;12(4):357-360.

116. Love MI, et al. Moderated estimation of fold change and dispersion for RNA-seq data with DESeq2. Genome Biol. 2014;15(12):550.

117. Nath AP, et al. Comparative analysis reveals a role for TGF- $\beta$ in shaping the residency-related transcriptional signature in tissueresident memory CD8+ T cells. PLoS One. 2019;14(2):e0210495.

118. Leek JT. svaseq: removing batch effects and other unwanted noise from sequencing data. Nucleic Acids Res. 2014;42(21):e161.

119. Eisenberg E, Levanon EY. Human housekeeping genes, revisited. Trends Genet. 2013;29(10):569-574.

120. $\mathrm{Mi} \mathrm{H}$, et al. PANTHER version 16: a revised family classification, tree-based classification tool, enhancer regions and extensive API. Nucleic Acids Res. 2020;49(d1):D394-D403. 